\title{
Determinação de padrões comportamentais na operação dos sistemas de iluminação e climatização em edifícios comerciais
}

\author{
Behavior patterns in operations of lighting and air \\ conditioning systems in commercial buildings
}

\section{Jéssica Castoldi Picchi Ciappina \\ Mariana Ragassi Urbano \\ Thalita Gorban Ferreira Giglio}

\section{Resumo}

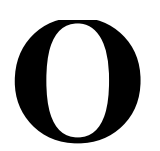

comportamento do usuário é um dos principais responsáveis pela divergência entre o consumo de energia real e o estimado em simulações computacionais. O presente trabalho identifica e categoriza os padrões de uso existentes na operação de sistemas da climatização e da iluminação em edificações comerciais. Para isso, foi realizada uma pesquisa de campo em Londrina, Paraná, em um edifício de fachadas em vidro de controle solar, layout flexível, core central e ventilação híbrida. Os dados foram levantados por meio de entrevistas com 100 usuários, abordando 72 fatores de influência na operação do edifício. Mediante o método de análise de cluster, identificou-se cinco padrões que diferem sobretudo no uso da ventilação natural e de persianas. Os testes estatísticos qui-quadrado de Pearson e de Kruskal-Wallis indicaram que os clusters são influenciados por aspectos contextuais e características projetuais, como exposição à radiação solar, preferências, hábitos, proximidade com as janelas e atividade laborativa. Além disso, o excesso de área envidraçada na fachada leste resultou na frequência de uso do ar-condicionado $20 \%$ maior. De forma geral, constatou-se que as ações dos usuários são heterogêneas, não sendo adequado representá-las perante um único padrão de uso.

Palavras-chave: Comportamento do usuário. Padrões de uso. Operação nos sistemas do edifício. Fatores de influência. Análise de cluster.

1Jéssica Castoldi Picchi Ciappina
1Universidade Estadual de Londrina
Londrina - PR - Brasil

${ }^{2}$ Mariana Ragassi Urbano 2Universidade Estadual de Londrina Londrina - PR - Brasil

${ }^{3}$ Thalita Gorban Ferreira Giglio 3Universidade Estadual de Londrina Londrina - PR - Brasil

Recebido em 21/12/20 Aceito em 01/04/21

\section{Abstract}

Occupant behavior is one of the main reasons to bridge the gap between predicted and actual energy consumption. The paper identifies and categorizes the existing usage patterns in operation of lighting systems and air conditioning in a commercial building. A questionnaire survey was applied in Londrina, Paraná, in a commercial building with facades constituted by glasses in which the low solar factor, flexible layout, central core and mixed ventilation. The data was collected through interviews with 100 users, approaching 72 influence factors in systems' operation. Using the cluster analysis method five patterns were identified, presenting differences mainly when it comes to the frequency of use of the natural ventilation and blinds. Pearson's chi-square and Kruskal-Wallis statistical tests were applied and identified this was influenced mainly by contextual aspects and design decisions such as exposure to solar radiation, preferences, habits, nearness to windows and work activity. Besides that, the overage of glass areas in the east facade resulted in a $20 \%$ more use of air-conditioning. This way, the actions of the users are heterogeneous, not being possible to represent them in a unique pattern behavior.

Keywords: User behavior. Energy use patterns. Building systems'operation. Influencing factors. Cluster analysis.

CIAPPINA, J. C. P.; URBANO, M. R.; GIGLIO, T. G. F. Determinação de padrões comportamentais na operação dos sistemas de iluminação e climatização em edifícios comerciais. Ambiente Construído, Porto Alegre, v. 22, n. 1, p. 71-94, jan./mar. 2022.

ISSN 1678-8621 Associação Nacional de Tecnologia do Ambiente Construído.

http://dx.doi.org/10.1590/s1678-86212022000100579 


\section{Introdução}

Diversas pesquisas afirmam que um dos fatores mais relevantes nas incertezas entre o consumo real das edificações e aquele estimado em programas de simulação está na influência dos usuários no momento de uso dos sistemas (HALDI; ROBINSON, 2008; JANDA, 2011; GUNAY; O’BRIEN; MORRISON, 2013; HONG et al., 2016; JIA; SRINIVASAN; RAHEEM, 2017; VECCHI et al., 2017; MARKOVIC et al., 2018; BAVARESCO; GHISI, 2018). A disparidade no consumo energético relativo aos usuários se concentra na diversidade de comportamentos e na forma como são operados os sistemas de janela, persiana, iluminação e ar-condicionado para obtenção do conforto (HONG; LIN, 2013; HONG et al., 2015; O'BRIEN et al., 2017). Dessa forma, os pesquisadores Hoes et al. (2009), Janda (2011), Gunay, O'Brien e Morrison (2013), Yan et al. (2015), O’Brien et al. (2017), Jia, Srinivasan e Raheem (2017), Hong et al. (2017), Borgstein, Lamberts e Hensen (2018) e Zhang et al. (2018) afirmam ser necessário compreender as atitudes do usuário na operação dos sistemas da edificação para gerenciar essa incerteza e obter uma melhor previsão do desempenho energético do edifício.

O comportamento do usuário na operação de sistemas em um edifício é influenciado por vários fatores, tanto internos quanto externos, individuais ou contextuais, que podem determinar diferentes ações para uso dos ambientes. Em outras palavras, os fatores comportamentais, complexos e diversificados, são os motivadores e os condutores que levam os usuários a adotarem determinada ação e a interagirem com os sistemas do edifício. Como consequência, tais ações apresentam reflexos no consumo total de energia (HALDI; ROBINSON, 2008; HOES et al., 2009; HALDI; ROBINSON, 2010; JANDA, 2011; ZHANG; BARRETT, 2012; FABI et al., 2011, 2012; O'BRIEN; GUNAY, 2014; HONG et al., 2015; YAN et al., 2015; STAZI; NASPI; D'ORAZIO, 2017; DELZENDEH et al., 2017).

Os inúmeros fatores podem estar relacionados aos aspectos ambientais (FABI et al., 2012; O'BRIEN; GUNAY, 2014; STAZI; NASPI; D'ORAZIO, 2017), fisiológicos e psicológicos (FABI et al., 2012), contextuais (O'BRIEN et al., 2017), sociais (HONG et al., 2017) e econômicos (KARJALAINEN, 2016; DELZENDEH et al., 2017). Na literatura, os fatores físico-ambientais são descritos como os mais significativos para analisar o comportamento do usuário nos edifícios comerciais (O’BRIEN; GUNAY, 2014). Esses constituem as características físicas do edifício, como, por exemplo, a geometria da edificação, a orientação solar, propriedades da envoltória, o tipo de sistemas e equipamentos instalados (STAZI; NASPI; D'ORAZIO, 2017; DELZENDEH et al., 2017), bem como as variáveis relacionadas ao conforto ambiental dos usuários, como temperatura, umidade, velocidade do ar, precipitação, ruído, iluminação e qualidade do ar (FABI et al., 2011, 2012).

Os fatores fisiológicos são definidos por Fabi et al. (2012) como os motivos que determinam a condição fisiológica das pessoas, vinculada às sensações, às necessidades do corpo humano e à satisfação com o conforto do ambiente interno (RUPP; VÁSQUEZ; LAMBERTS, 2015). Em relação aos fatores psicológicos, Fabi et al. (2012) entendem como sendo os aspectos que satisfazem as expectativas dos usuários, como a segurança, o conhecimento, o hábito e a percepção. E Stazi, Naspi e D'Orazio (2017) acrescentam a privacidade e a vista do exterior.

Os fatores contextuais encontrados na literatura estão ligados à vista, à ocupação, à complexidade dos sistemas de automação (O'BRIEN; GUNAY, 2014), à estação do ano e à hora do dia (HONG et al., 2015). Esses fatores são difíceis de ser mensurados e quantificados, o que traz complexidade na obtenção de dados e dificuldade de estimá-los nas simulações de energia. Contudo, seu conhecimento é importante na medida em que os projetistas devem compreender que muitas vezes os usuários não se comportam como esperado e devem perceber que as decisões dos usuários auxiliarão no desenvolvimento de projetos mais eficientes (O’BRIEN; GUNAY, 2014).

Quanto ao fator social, têm-se a rotina (STAZI; NASPI; D'ORAZIO, 2017), a saúde, a riqueza pessoal, a cultura ambiental e o estilo de vida (O’BRIEN et al., 2017). Apesar de serem pouco explorados nas pesquisas relacionadas ao uso de energia, segundo Hong et al. (2017), são relevantes para que a investigação seja completa. Além disso, sua incorporação nos estudos do comportamento representa uma irrefutável tendência. Nesse sentido, há uma diversidade de influências que o usuário pode receber, as quais refletem em diferentes padrões de uso.

Nas simulações termoenergéticas utilizadas para previsões de consumo, o padrão de uso adotado não abrange todos os aspectos comportamentais dos usuários demonstrados na literatura. Desse modo, a lacuna entre a programação das simulações e a realidade deve ser suprida com programações de rotinas de usos reais para que, com isso, sejam atingidas estimativas mais fidedignas do que ocorre no cenário real (HOES

72 Ciappina, J. C. P.; Urbano, M. R.; Giglio, T. G. F. 
et al., 2009; FENG; YAN; HONG, 2015; YAN et al., 2015; SUN; HONG, 2017). Além de tomar conhecimento sobre os possíveis padrões de uso existentes, os pesquisadores têm buscado encontrar modelos de ocupação e das ações de adaptação dos usuários para simulações de desempenho mais realistas. No entanto, ainda há discussões sobre a modelagem do comportamento, pois o modelo é específico para cada caso (GAETANI; HOES; HENSEN, 2016). As modelagens e os métodos, até o momento, usam dados de um pequeno número de padrões de usuários, com suposições generalistas para a simulação de desempenho das edificações, sem caracterizar a diversidade de ocupação e comportamentos (O'BRIEN et al., 2017). No contexto brasileiro, Bavaresco e Ghisi (2021) afirmam que os dados nacionais relativos aos padrões comportamentais são insuficientes.

Para uma compreensão assertiva do uso da energia nos edifícios, devem ser priorizados os estudos com foco no usuário e embasados no levantamento de informações de dados reais, pois esses permitem um melhor entendimento e uma estimativa mais próxima daquilo que corresponderá ao comportamento do usuário (D’OCA; HONG, 2015). Diante disso, esta pesquisa visa identificar, compreender e categorizar os padrões de uso existentes em um edifício comercial que possam ser aplicados em estudos por simulação computacional.

\section{Método}

No presente artigo foram identificados e categorizados diferentes padrões de uso e operação dos sistemas de ar condicionado, iluminação artificial, janelas e persianas em um edifício comercial. Considerando a importância das ações reais no controle dos sistemas (YAN et al., 2015), foi realizada uma pesquisa de campo por meio de entrevistas com 100 usuários do edifício. Para o levantamento dos dados, foram considerados 72 fatores de influência, elencados por Fabi et al. (2012) e sistematizados por Hong et al. (2015). Foi adotado o método de análise de cluster por agrupamento hierárquico aglomerativo (HAN; KAMBER; PEI, 2012) para identificar e quantificar os diferentes padrões de uso existentes. Por fim, foram aplicados os testes estatísticos qui-quadrado de Pearson e de Kruskal-Wallis (FIELD, 2009) para verificar os fatores de influência em cada grupo. O fluxograma da Figura 1 sintetiza os procedimentos adotados na pesquisa.

\section{Edifício analisado}

Construído em 2014, o edifício comercial escolhido está localizado na cidade de Londrina, Paraná, Brasil (latitude $23^{\circ} 17^{\prime} 34^{\prime \prime}$ sul e longitude $51^{\circ} 10^{\prime} 24^{\prime \prime}$ oeste). Segundo a NBR 15220-3 (ABNT, 2005), a cidade é caracterizada por verões quentes e úmidos, e invernos secos. Está inserida no grupo climático 15 do INI-C (INSTITUTO..., 2021), caracterizado com temperatura média anual entre $21^{\circ} \mathrm{C}$ e $25^{\circ} \mathrm{C}$, e amplitude média anual maior do que $11,9^{\circ} \mathrm{C}(\mathrm{RORIZ}, 2014)$.

A Figura 2 apresenta as fachadas do edifício e suas orientações solares.

Figura 1 - Fluxograma das etapas e dos procedimentos da pesquisa

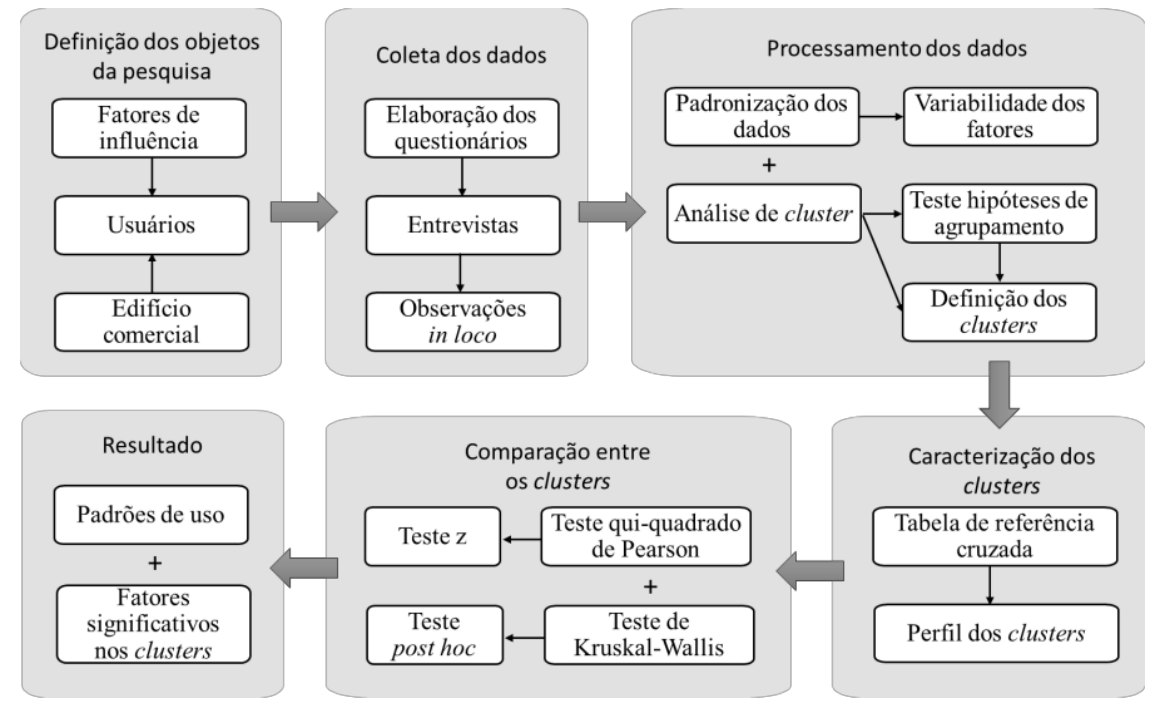


Figura 2 - Imagens das fachadas da edificação analisada

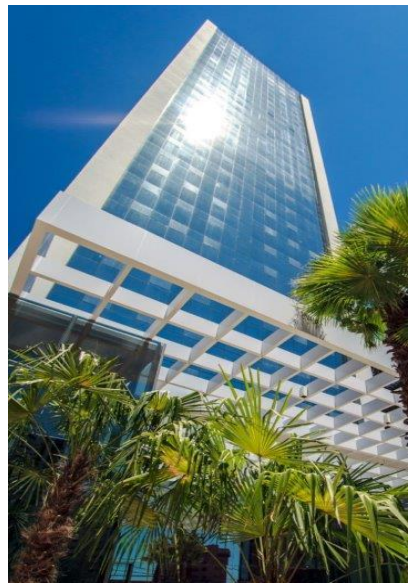

(a) Fachada leste

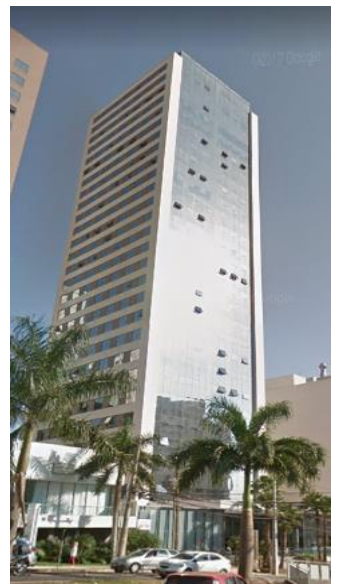

(b) Fachadas sul e leste

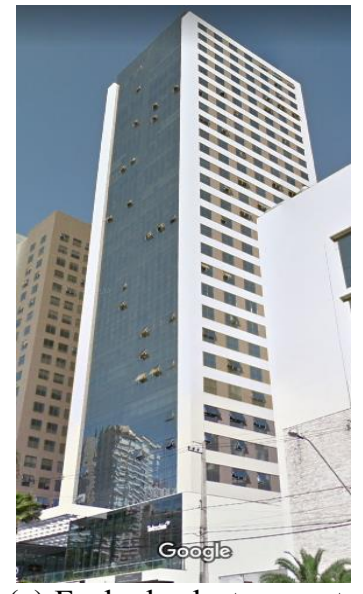

(c) Fachadas leste e norte

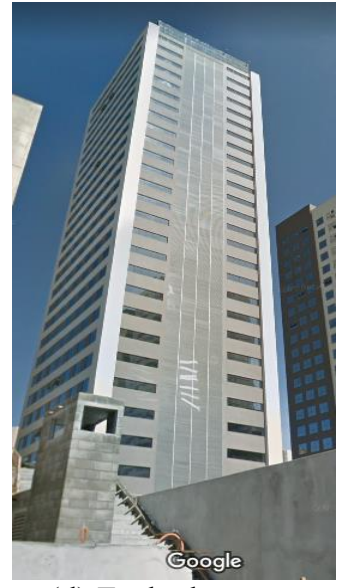

(d) Fachada oeste

Fonte: Google Maps (2020).

O edifício possui 27 andares de pavimento-tipo, subdividido em quatro salas comerciais, as quais podem ser unificadas para três, duas ou uma única sala por pavimento, conforme representado na Figura 3. A opção da menor sala tem $94,00 \mathrm{~m}$, e a da maior sala, $468,13 \mathrm{~m}$. Atualmente, o edifício encontra-se subdividido em 77 salas comerciais. A torre totaliza 15.278,76 m construídos e abrange uma envoltória com 9.135,51 m .

Em geral, a geometria dos edifícios comerciais verticais pode ser classificada seguindo a localização do núcleo ou core (espaço destinado à circulação vertical, à escada, a elevadores e a áreas de apoio da edificação). Com base nos estudos de Pisani e Figueiredo (2011) e de acordo com as variações expostas na Figura 3, o edifício comercial apresenta core localizado no centro da planta, sem contato com o ambiente externo. Além disso, tem layout ${ }^{1}$ flexível com piso elevado, forro rebaixado e modular de placas removíveis, modulação livre das salas em volta do core, o que permite flexibilidade para disposição de paredes, mobiliários e usuários (LIU, 2010; MARIANO, 2013).

Em relação à ventilação, o edifício funciona de forma híbrida, com a possibilidade de escolha pelo usuário do sistema de climatização artificial ou da ventilação natural para a obtenção do conforto térmico. A climatização híbrida dos ambientes é comumente adotada nos edifícios comerciais brasileiros.

Outra característica notável no edifício investigado e presente nos edifícios comerciais são as fachadas envidraçadas. A fachada principal, voltada para a orientação leste, apresenta extensa pele de vidro e o maior percentual de aberturas na fachada, com $\mathrm{PAF}_{\text {leste }}$ de $56,25 \%{ }^{2}$. Tanto as aberturas da fachada leste quanto as das demais fachadas são do tipo projetante e possuem vidro laminado de $8 \mathrm{~mm}$, com fator solar de $0,26 \mathrm{e}$ transmitância térmica de 5,6 W/m K. Demais parâmetros aferidos estão delineados na Tabela 1 .

\section{Sistematização dos fatores de influência e coleta de dados}

Considerando os diversos fatores que influenciam o comportamento do usuário, adotou-se a estrutura metodológica proposta por Hong et al. (2015), a qual apresenta uma classificação baseada em quatro elementos representados pela sigla DNAS (do inglês drivers, needs, actions e systems). Os drivers são os aspectos que induzem os usuários a atenderem a suas necessidades físicas, fisiológicas e psicológicas. Esses são classificados em cinco categorias: edifício, usuário, condições ambientais, sistemas instalados e tempo. Needs são os requisitos a serem atendidos para a satisfação dos usuários no ambiente, sendo relacionados a suas necessidades físicas, como o conforto ambiental e a qualidade do ambiente, ou não físicas, como a privacidade e a vista externa. Actions são as interações e as atitudes que os usuários realizam para obter conforto. E systems correspondem aos equipamentos com que os usuários interagem para restabelecer o conforto, interferindo, assim, no consumo de energia do edifício. No caso de um usuário que trabalha em

${ }^{1} 0$ layout do ambiente refere-se ao tipo de sala em que o usuário entrevistado exerce seu trabalho. A sala pode ser de uso individual, caracterizada como privada, ou de uso compartilhado com outros usuários, identificada como de layout aberto.

${ }^{2} \mathrm{O}$ cálculo considera apenas o vão da abertura, desconsiderando a sobreposição que existe na composição formada pelo vidro, pela câmara de ar e pelos elementos opacos, como vigas, pilares e vedações em alvenaria. 
uma sala com uso da ventilação natural, no decorrer do dia a temperatura interna aumenta e o usuário começa a sentir desconforto térmico. Diante disso, abre a janela para entrar ar fresco e restabelecer seu nível de conforto. Nesse exemplo citado por Hong et al. (2015), o driver é a temperatura interna, a need o conforto térmico, a action a abertura da janela e o system a janela.

Figura 3 - Variações na planta baixa do pavimento-tipo do edifício analisado
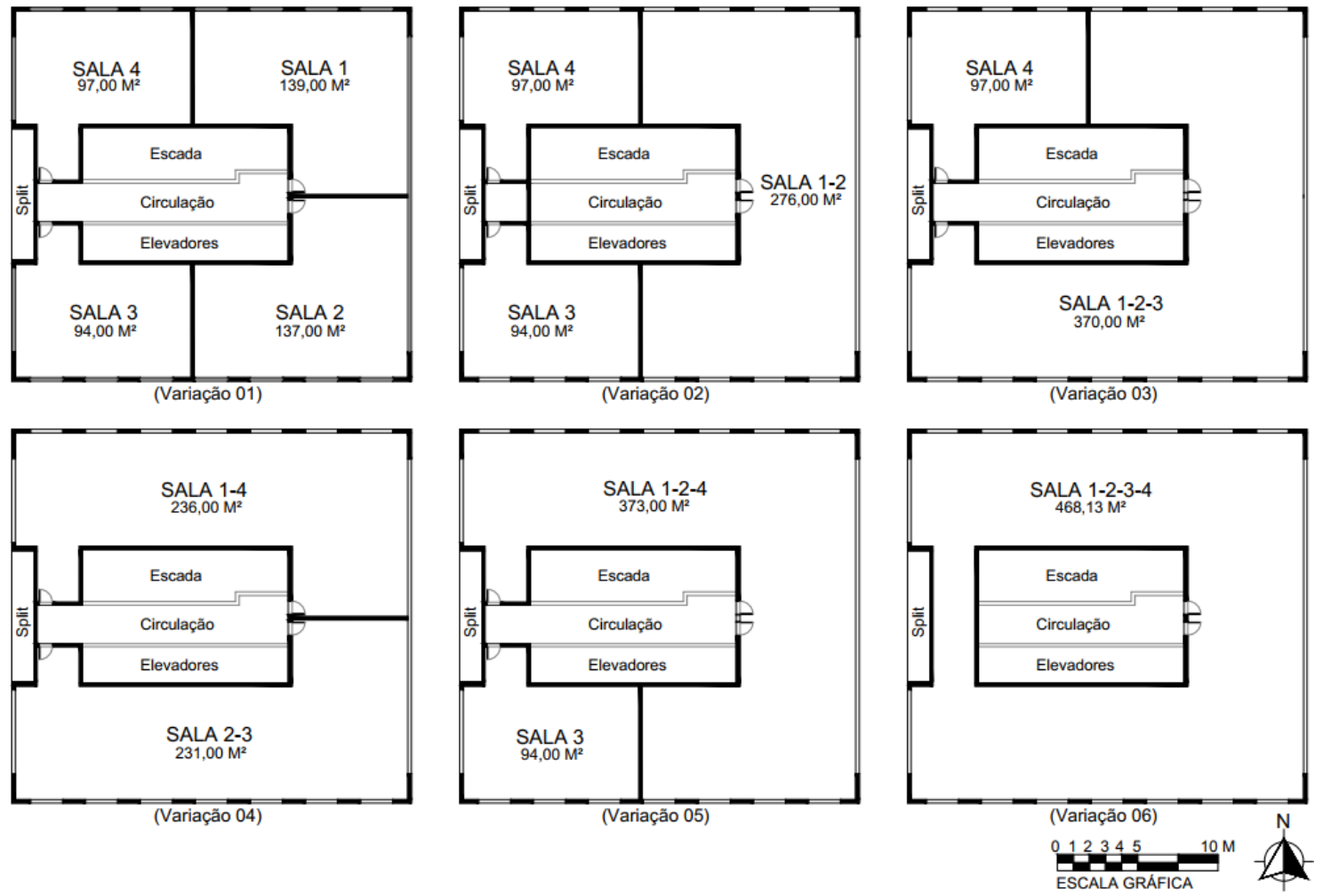

Tabela 1 - Parâmetros da edificação de estudo

\begin{tabular}{l|c|c}
\hline \multicolumn{1}{c|}{ Parâmetros } & Símbolo/Sigla & Valore** \\
\hline Área total construída & Atot & $15.278,76 \mathrm{~m}$ \\
Área de projeção da cobertura & $\mathrm{Apcob}$ & $565,88 \mathrm{~m}$ \\
Área de projeção da edificação & $\mathrm{Ape}$ & $565,88 \mathrm{~m}$ \\
Volume total & $\mathrm{Vtot}$ & $51.455,05 \mathrm{~m}$ \\
Área da envoltória & $\mathrm{Aenv}$ & $9.135,51 \mathrm{~m}$ \\
Percentual de abertura fachada leste & $\mathrm{PAF}_{\text {leste }}$ & $56,25 \%$ \\
Percentual de abertura fachada oeste & $\mathrm{PAF}_{\mathrm{o}}$ & $16,40 \%$ \\
Percentual de abertura fachada norte & $\mathrm{PAF}_{\text {norte }}$ & $32,42 \%$ \\
Percentual de abertura fachada sul & $\mathrm{PAF}_{\text {sul }}$ & $32,42 \%$ \\
Percentual de abertura fachada total & $\mathrm{PAF}_{\text {total }}$ & $34,31 \%$ \\
Ângulo vertical de sombreamento & $\mathrm{AVS}^{*}$ & 0 \\
Ângulo horizontal de sombreamento & $\mathrm{AHS}$ & 0 \\
Dias de ocupação & - & 5 \\
Taxa de ocupação (m /usuário) & - & 7,7 \\
Transmitância térmica das paredes & $\mathrm{Upar}$ & $1,48 \mathrm{~W} / \mathrm{m} \cdot \mathrm{K}$ \\
Capacidade térmica das paredes & $\mathrm{CT}$ & $247,32 \mathrm{~kJ} / \mathrm{m} . \mathrm{K}$ \\
\hline Absortância solar das paredes & $\alpha$ & 0,39 \\
Transmitância térmica do vidro & $\mathrm{Uvid}$ & $5,6 \mathrm{~W} / \mathrm{m} . \mathrm{K}$ \\
\hline Fator solar & $\mathrm{FS}$ & 0,26 \\
\hline
\end{tabular}

Nota: *dados referentes à torre vertical (pavimentos-tipo). 
Ao todo foram investigados 72 fatores de influência (Quadro 1) no comportamento do usuário, subdivididos em seis categorias (drivers) de análise:

(a) edifício (características termofísicas da edificação);

(b) espaço (relativo às salas comerciais);

(c) tempo (período de ocupação);

(d) condições ambientais (relativas ao momento da análise);

(e) sistemas (ar-condicionado, iluminação artificial, janelas e dispositivos internos de sombreamento); e

(f) usuários.

Nesta última categoria foram contempladas needs físicas e não físicas.

As entrevistas foram organizadas segundo um formulário que abarcava os 72 fatores de influência mencionados. Na primeira etapa, para a seleção das salas, foram considerados fatores como a diversidade existente em relação à natureza da atividade exercida, a área útil, o número de usuários presentes por metro quadrado e a orientação solar. Dessa forma, das 77 salas ocupadas no edifício, foram selecionadas 30 salas com variação nas características citadas, sendo possível obter uma amostra heterogênea no edifício em estudo. Na segunda etapa, após a seleção das salas, foram entrevistados 100 usuários do edifício que concordaram em participar da pesquisa e observados os sistemas presentes em suas estações de trabalho. O cálculo do tamanho da amostra foi realizado levando-se em consideração o total de 1.984 usuários do edifício, $\mathrm{p}=0,5$, margem de erro de 0,096 e nível de confiança de 95\%, usando-se a Equação 1 .

$n=\frac{\mathrm{z}^{2} \mathrm{p}(1-\mathrm{p}) \mathrm{N}}{\mathrm{Ne}^{2}+\mathrm{p}(1-\mathrm{p}) \mathrm{z}^{2}}$

Onde:

$\mathrm{z}=$ valor associado ao nível de confiança $(\mathrm{z}=1,96)$;

$\mathrm{p}=$ proporção populacional;

$\mathrm{N}=$ tamanho da população; e

$\mathrm{e}=$ margem de erro

Quanto à coleta de dados, a pesquisa foi limitada ao período de primavera e verão, entre os dias 24 de outubro de 2019 e 21 fevereiro de $2020^{3}$. No entanto, foi possível obter o histórico do consumo de energia elétrica referente ao período de 1 ano das salas investigadas por meio das faturas de energia das unidades.

Complementa-se que a pesquisa foi aprovada pelo Comitê de Ética em Pesquisa envolvendo Seres Humanos da Universidade Estadual de Londrina, sob o Certificado de Apresentação para Apreciação Ética (Caae) de número 18792719.8 .0000 .5231 .

\section{Análise estatística}

Para identificar e quantificar os grupos de padrões de uso existentes, foi aplicada a técnica de análise de clusters usando-se o algoritmo TwoStep Cluster do software SPSS 20 (SPSS, 2011), que possibilitou realizar a análise com variáveis qualitativas e quantitativas.

A definição do número de clusters adequado à amostra da pesquisa foi estabelecida com base na silhueta de coesão e separação proposta por Rousseeuw (1987). A distância foi calculada para cada objeto, verificando se estavam distribuídos adequadamente, de acordo com a Equação 2 (KUMAR; STEINBACH; TAN, 2009).

$S_{i=\frac{\left(b_{i}-a_{i}\right)}{\max \left(a_{i}, b_{i}\right)}}$

Eq. 2

Onde:

$\mathrm{S}_{\mathrm{i}}=$ média das silhuetas de cada objeto;

$\mathrm{a}_{\mathrm{i}}=$ distância média em relação a todos os objetos do mesmo grupo; e

$b_{i}=$ distância média em relação a todos os objetos dos demais grupos.

${ }^{3}$ Período anterior à data em que começou a quarentena devido à pandemia de covid-19, iniciada em 16 de março de 2020 na cidade de realização do estudo. 
Quadro 1 - Definição dos fatores de influência

\begin{tabular}{|c|c|c|c|}
\hline Categ. & Subcategoria & Fatores & Níveis de ação \\
\hline \multirow{13}{*}{ 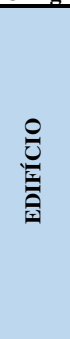 } & \multirow{3}{*}{ Componente } & Materiais construtivos & Tipos de materiais \\
\hline & & Quantidade de salas comerciais & $\mathrm{n}^{\circ}$ de salas ocupadas \\
\hline & & Quantidade de aberturas & $\mathrm{n}^{\circ}$ de janelas \\
\hline & \multirow{7}{*}{ Propried. } & Taxa de ocupação & $\mathrm{m}$ /usuário \\
\hline & & Área construída & $\mathrm{m}$ \\
\hline & & Transmitância térmica & Upar (W/m.K) \\
\hline & & Absortância solar & $\alpha$ \\
\hline & & Capacidade térmica & $\mathrm{CT}(\mathrm{kJ} / \mathrm{m} . \mathrm{K})$ \\
\hline & & Percentual de aberturas & $\%$ \\
\hline & & Fator solar do vidro & FS \\
\hline & \multirow{3}{*}{ Localização } & Orientacão solar & $\mathrm{N} / \mathrm{S} / \mathrm{L} / \mathrm{O}$ \\
\hline & & Entorno & Ruas, edifícios, praças \\
\hline & & Existência de ruas movimentadas & $\mathrm{Sim} /$ Não \\
\hline & & Número de usuários & $\mathrm{n}^{\circ}$ \\
\hline & & Taxa de ocupação & $\mathrm{m}$ /usuário \\
\hline & & Área útil da sala & $\mathrm{m}$ \\
\hline en & & Consumo médio mensal & $\mathrm{kWh} /$ mês \\
\hline 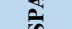 & Caract. & Orientacão solar da sala & $\mathrm{N} / \mathrm{S} / \mathrm{L} / \mathrm{O}$ \\
\hline & & Natureza da atividade da sala & Serviço que realiza \\
\hline & & Presença de servidor & Sim / Não \\
\hline & & Equip. atípicos $\mathrm{c} /$ demanda energia & Sim / Não \\
\hline & & Data & $\mathrm{dd} / \mathrm{mm} / \mathrm{aa}$ \\
\hline$\sum_{i=1} 0$ & Diário & Horário do dia & Começo/ Meio/ Fim da manhã ou da tarde \\
\hline & & Dia da semana & Seg. / Ter. / Qua. / Quin. / Sex. \\
\hline & & Temperatura externa & ${ }^{\circ} \mathrm{C}$ \\
\hline $\mathscr{\Omega}$ & Condições & Umidade relativa externa & 0 a $100 \%$ \\
\hline 记它 & externas & Estado climático no momento & $\begin{array}{l}\text { Ensolarado / Nublado/Chuvoso / } \\
\text { Chuvas isoladas/Parcialmente nublado }\end{array}$ \\
\hline$\overline{\mathrm{\theta}}$ 될 & & Temperatura interna & ${ }^{\circ} \mathrm{C}$ \\
\hline 写㒸 & Condições & Umidade relativa interna & 0 a $100 \%$ \\
\hline & internas & Nível de pressão sonora no ambiente & $\mathrm{dB}$ \\
\hline & & Iluminância no plano de trabalho & lux \\
\hline & & Existência do sistema & Sim/Não \\
\hline & Tonela & Estado & Aberta / Fechada / Parc. aberta \\
\hline & Janela & Quantidade de janelas & $\mathrm{n}^{\circ}$ de janelas \\
\hline & & Quantidade de janelas fixas & $\mathrm{n}^{\circ}$ de janelas fixas \\
\hline & & Existência do sistema & Sim/Não \\
\hline & Elemento interno & Estado & Aberta / Fechada / Parc. Aberta \\
\hline & de sombreamento & Cor & Nome da cor \\
\hline & & Material & Alumínio/ Tecido/ Tela solar/ Outro \\
\hline & & Estado & Ligada / Desligada / Parc. ligada \\
\hline & & Tipo de luminárias & Refletora / Spot / Placa leitosa/Placa de LED \\
\hline & & Quantidade de cada tipo de luminária & $\mathrm{n}^{\circ}$ de luminárias \\
\hline$\sum_{i=1}$ & Jluminac̃ & Tipo de lâmpadas & LED / Fluorescente/Incandescente / Halógena \\
\hline 穷 & Iluminaçao & Quantidade de cada tipo de lâmpada & $\mathrm{n}^{\circ}$ de lâmpadas \\
\hline$\frac{2}{n}$ & & Divisão de circuitos & Sim / Não \\
\hline & & Tipo de acionamento & Manual / Automático \\
\hline & & Acionamento independente próximo às janelas & Sim / Não \\
\hline & & Existência do sistema & Sim/Não \\
\hline & & Estado & Ligado / Desligado \\
\hline & & Tipo do ar-condicionado & Split parede / Cassete / Central \\
\hline & & Quantidade de ar-condicionado & $\mathrm{n}^{\circ}$ de ares-condicionados \\
\hline & Ar-condic. & Tipo de operação & Frio / Ciclo reverso \\
\hline & & Capacidade de refrigeração & $\mathrm{Btu} / \mathrm{h}$ \\
\hline & & Classif. de eficiência energética & $\mathrm{A} / \mathrm{B} / \mathrm{C} / \mathrm{D} / \mathrm{E}$ \\
\hline & & Temperatura programada, se ligado & ${ }^{\circ} \mathrm{C}$ \\
\hline & & Localização do usuário & $\mathrm{N} / \mathrm{S} / \mathrm{L} / \mathrm{O}$ \\
\hline & Localização & Proximidade do usuário com a janela & Próximo / Intermediário / Distante \\
\hline & & Lay out do ambiente & Lay out aberto / Lay out privado \\
\hline & & Gênero & Feminino / M asculino \\
\hline & & Idade & Anos \\
\hline & & Atividade que o usuário exerce & Profissão \\
\hline & A trihutos & Taxa metabólica & $70 \mathrm{~W} / \mathrm{m}, 93 \mathrm{~W} / \mathrm{m}, 116 \mathrm{~W} / \mathrm{m}$ \\
\hline & Atributos & Dias de ocupação & $\mathrm{n}^{\circ}$ de dias/semana \\
\hline & & Horas de ocupação & Horário de chegada / saída \\
\hline & & Permanência na sala no horário de almoço & Sim / Não \\
\hline & & Responsável pelo pagamento - conta energia & Sim / Não \\
\hline & & Vestimenta & $0,3 / 0,5 / 0,7 / 1,0 / 1,2$ clo \\
\hline & Estado & Condição no momento & Chegar / Permanece / Sair do ambiente \\
\hline$\underline{\underline{2}}$ & & Conforto térmico no momento & Satisfeito / Indiferente / Insatisfeito \\
\hline$\frac{0}{4}$ & & Frequência de operação & Sempre/Ás vezes / Nunca \\
\hline 2 & & Conforto / Desconforto térmico & Sim / Não \\
\hline 3 & & Conforto / Desconforto visual & Sim / Não \\
\hline & & Conforto / Desconforto acústico & Sim / Não \\
\hline & & Qualidade do ar interno & Sim / Não \\
\hline & & Momento de chegada / saída & Sim / Não \\
\hline & & Ocorrência de chuva e vento & Sim / Não \\
\hline & Atitudes & Hábito/rotina & Sim / Não \\
\hline & Atitudes & Preferência & Sim / Não \\
\hline & & Código de vestimenta & Sim / Não \\
\hline & & Regimento da empresa & Sim / Não \\
\hline & & Atendimento cliente/paciente & Sim / Não \\
\hline & & Solicitação de outros colegas & Sim / Não \\
\hline & & Privacidade & Sim / Não \\
\hline & & Setpoint do ar-condicionado & ${ }^{\circ} \mathrm{C}$ \\
\hline & & Perfil de consumo de energia & Econômico/Moderado/ Desperdiçador \\
\hline
\end{tabular}


A silhueta si possui variação entre - 1 e 1 , sendo superior a 0,5 o valor que expressa uma qualidade aceitável dos clusters formados (KUMAR; STEINBACH; TAN, 2009). Assim, a silhueta foi utilizada para validar o número apropriado de clusters.

As variáveis de entrada utilizadas para classificação dos clusters foram os fatores e os níveis de ação dispostos no Quadro 1. Elas foram selecionadas de acordo com o grau de importância obtido no processo de agrupamento do SPSS 20 , que varia de 0 a 1 . Quando é 0 ou próximo de 0 , a variável não deve ser incluída, pois não será relevante na formação dos clusters; se o grau de importância for maior do que 0 ou próximo de 1, a variável deve ser incluída.

Desse modo, para a formação dos clusters, foram analisadas hipóteses de agrupamentos com combinações entre 155 e 55 variáveis resultantes dos níveis de ação elencados no estudo. Os agrupamentos progrediram com a permanência das variáveis relevantes e a eliminação das variáveis que não foram significativas. Além disso, devido ao grande número de dados coletados e à semelhança de importância das variáveis dentro de um mesmo driver, traçaram-se hipóteses de agrupamento com base nos drivers, suprimindo os drivers com variáveis de menor importância.

Em síntese, seis hipóteses de agrupamentos foram testadas até atingir um agrupamento considerado satisfatório pela silhueta de coesão e separação, e consoante com as observações identificadas no local. As hipóteses investigadas foram:

$1^{\text {a) }}$ agrupamento com todas as variáveis de todos os drivers;

$2^{\mathrm{a}}$ ) agrupamento com variáveis dos drivers espaço, sistema e usuários;

$3^{a}$ ) agrupamento com variáveis dos drivers espaço e usuários;

$4^{a}$ ) agrupamento com variáveis dos drivers sistema e usuários;

$5^{\mathrm{a}}$ ) agrupamento com todas as variáveis do driver usuários; e

$6^{\mathrm{a}}$ ) agrupamento com variáveis referentes à localização e a atitudes do driver usuários.

Adotou-se o agrupamento alcançado na sexta hipótese para definição dos padrões de uso, pois esse obteve a qualidade 0,5 , considerada adequada pela silhueta de coesão e separação. Os clusters foram caracterizados com base na representatividade das variáveis que os constituíram e na frequência dos fatores, por meio da tabela de referência cruzada, que estabelece as frequências absolutas das variáveis para cada cluster.

Após a formação dos clusters, foram identificados os fatores comportamentais que diferem entre si e são característicos entre os grupos. Nesta etapa, a grande diversidade dos fatores coletados e a diferença de parâmetros existentes entre eles demandaram uma padronização dos dados. Para isso, os dados qualitativos foram transformados em atributos numéricos, sendo transformadas variáveis de duas alternativas em binárias e, para as demais, adotados valores como $1,2,3,4 \ldots$ Em seguida, foram normalizados por meio da estatística escores-z (FIELD, 2009), conforme a Equação 3.

$z_{i}=\frac{X_{i}-\overline{X_{N}}}{S}$

Onde:

$Z_{\mathrm{i}}=$ número de desvios padrão a contar da média;

$\mathrm{x}_{\mathrm{i}}=$ valor real a ser transformado;

$X_{N}=$ valor médio do atributo relativo aos 200 dados; e

$\mathrm{S}=$ desvio padrão.

Assim, os dados normalizados auxiliaram no entendimento da variação dos fatores entre os clusters e na caracterização de cada grupo.

Por fim, para comparar as variáveis qualitativas entre os clusters, foi realizado o teste qui-quadrado de Pearson (FIELD, 2009), seguido do teste z. O resultado do teste z é apresentado com letras. Quando aponta letras iguais para a mesma variável, indica que não há diferenças entre as porcentagens da variável entre os clusters; e, se as porcentagens são seguidas de letras diferentes, há diferenças. Para as comparações das variáveis quantitativas entre os clusters, realizou-se o teste de Kruskal-Wallis, seguido do teste post hoc para comparar as diferentes combinações dos grupos (FIELD, 2009). Ambos os testes foram obtidos com o software SPSS, sendo adotado o nível de significância de $\alpha=0,05$. Se o p-valor obtido nos testes for menor que $\alpha$, rejeita-se a hipótese nula. 
O teste qui-quadrado de Pearson, representado por $x^{2}$, foi calculado com base na comparação de frequências observadas com as frequências esperadas. Dado que as variáveis são categóricas, não é possível trabalhar com médias, sendo necessário adotar valores esperados. Assim, a frequência observada é a contagem real da amostra e a frequência esperada é um valor estimado ao acaso para cada célula da tabela por meio da Equação 4. $\mathrm{O}$ valor do $x^{2}$ foi calculado comparando as frequências conforme a Equação 5, consequentemente, foi possível verificar a associação entre as variáveis (FIELD, 2009).

$E_{i j}=\frac{\begin{array}{c}\text { Total }_{\text {da linh }}{ }_{i}{ }^{X} \begin{array}{c}\text { Total } \\ \text { da coluna } \\ j\end{array} \\ n\end{array}}{x^{2}}=\sum_{i=1}^{s} \sum_{j=1}^{r} \frac{\left(O_{i j}-E_{i j}\right)^{2}}{E_{i j}}$

Onde:

$E_{\mathrm{ij}}=$ número de casos esperados na interseção da linha i com a coluna j;

$\mathrm{O}_{\mathrm{ij}}=$ frequência observada na interseção da linha $\mathrm{i}$ com a coluna $\mathrm{j}$;

$\mathrm{n}=$ tamanho da amostra; e

$\chi^{2}=$ estatística do teste.

As hipóteses do teste qui-quadrado são:

(a) nula, quando não há associação entre o fator em estudo e os clusters; e

(b) alternativa, quando há associação entre o fator em estudo e os clusters.

Complementa-se que, para as variáveis categóricas, quando os valores das frequências observadas e esperadas forem semelhantes e o valor do $x^{2}$ próximo de zero, não é significativa a associação entre as variáveis. Contudo, quanto maior for a diferença entre os valores das frequências observadas e esperadas, maior é o nível de significância e, consequentemente, há a associação entre as variáveis.

Para as variáveis quantitativas, foi usado o teste não paramétrico de Kruskal-Wallis para verificar diferenças entre os grupos em relação a determinada variável. A estatística do teste, representado por $\mathrm{H}$, foi calculada com base na Equação 6 (FIELD, 2009).

$H=\frac{12}{N(N+1)} \sum_{i=1}^{k} \frac{R_{i}^{2}}{n_{i}}-3(N+1)$

Eq. 6

Onde:

$\mathrm{H}=$ estatística do teste;

$\mathrm{N}=$ total da amostra;

$\mathrm{n}_{\mathrm{i}}=$ tamanho amostral de cada um dos grupos;

$\mathrm{R}_{\mathrm{i}}=$ soma dos postos ${ }^{4}$ para cada grupo; $\mathrm{e}$

$\mathrm{k}=$ número de grupos.

As hipóteses do teste Kruskal-Wallis são:

(a) nula, quando não há diferenças no fator em estudo em relação aos clusters; e

(b) alternativa, quando há diferenças no fator em estudo em relação aos clusters.

O método aplicado permitiu definir os padrões de operação nos sistemas existentes na edificação comercial analisada e os fatores de influência que mais se diferenciaram entre os padrões identificados. Tais dados favorecem o conhecimento do comportamento do usuário para incorporá-los em simulações termoenergéticas de edifícios comerciais, bem como dos fatores relevantes a serem considerados em projetos arquitetônicos.

${ }^{4}$ Postos referem-se à classificação ordenada dos dados observados em todos os grupos em uma única série, formando uma sequência (HACKBARTH NETO; STEIN, 2003). 


\section{Resultados e discussões}

\section{Variabilidade nos dados obtidos}

Diante dos 72 fatores de influência na operação dos sistemas levantados nesta pesquisa, verificou-se grande variabilidade nos dados, decorrente da heterogeneidade que existe nesse contexto. Destacam-se, de maneira geral, a diversidade encontrada na natureza da atividade exercida nas salas comerciais, a taxa de ocupação e o consumo de energia elétrica.

As 30 salas investigadas abrangem 10 atividades de naturezas distintas, como administrativo (10\%), advocacia $(10 \%)$, arquitetura/engenharia $(10 \%)$, atividade física $(3 \%)$, clínica de psicologia $(7 \%)$, clínica médica $(17 \%)$, comercial $(3 \%)$, contabilidade/financeiro $(23 \%)$, odontologia $(7 \%)$ e tecnologia da informação (10\%). Dessas salas, 63\% apresentam distribuição com layout aberto e $37 \%$ layout privado. Dos entrevistados, apenas $6 \%$ estavam em salas de layout privado com ausência de janelas e contato com a envoltória. As demais salas apresentam possibilidade de ventilação natural e influência direta da envoltória por ao menos duas orientações solares.

O consumo de energia elétrica apresentou grande variação entre as salas, de $1,41 \mathrm{kWh} / \mathrm{m}$ a $15,43 \mathrm{kWh} / \mathrm{m}$, e a taxa de ocupação variou de 5,88 m/usuário a 55,20 m/usuário entre a maior e a menor ocupação. Salienta-se que a INI-C (INSTITUTO..., 2021) estabelece um valor representativo de $10 \mathrm{~m} /$ usuário para caracterizar a taxa de ocupação em edifícios de escritórios. Na Figura 4 têm-se o consumo e a taxa de ocupação ordenados por atividade. Constata-se que as atividades relativas à tecnologia da informação apresentam consumo mais expressivo $\left(12,82 \mathrm{kWh} / \mathrm{m}^{2}\right)$ e maior número de usuários por metro quadrado $(7,79$ $\mathrm{m}$ /usuário), considerando somente usuários com atividade laborativa no edifício. Por outro lado, as clínicas de psicologia, que também apresentaram alta taxa de ocupação (10,16 m /usuário), possuem baixo consumo de energia por unidade de área $\left(5,48 \mathrm{kWh} / \mathrm{m}^{2}\right)$. Assim, percebe-se que não existe uma relação direta entre consumo e taxa de ocupação. Em Gunay, O’Brien e Morrison (2013) compreende-se que diferentes atividades demandam usos distintos dos sistemas. Além disso, o consumo não está associado somente aos sistemas de climatização e iluminação, tampouco somente à taxa de ocupação, sendo influenciado por demais equipamentos elétricos presentes no local.

\section{Figura 4 - Consumo de energia elétrica em média mensal e taxa de ocupação em cada natureza de atividade}

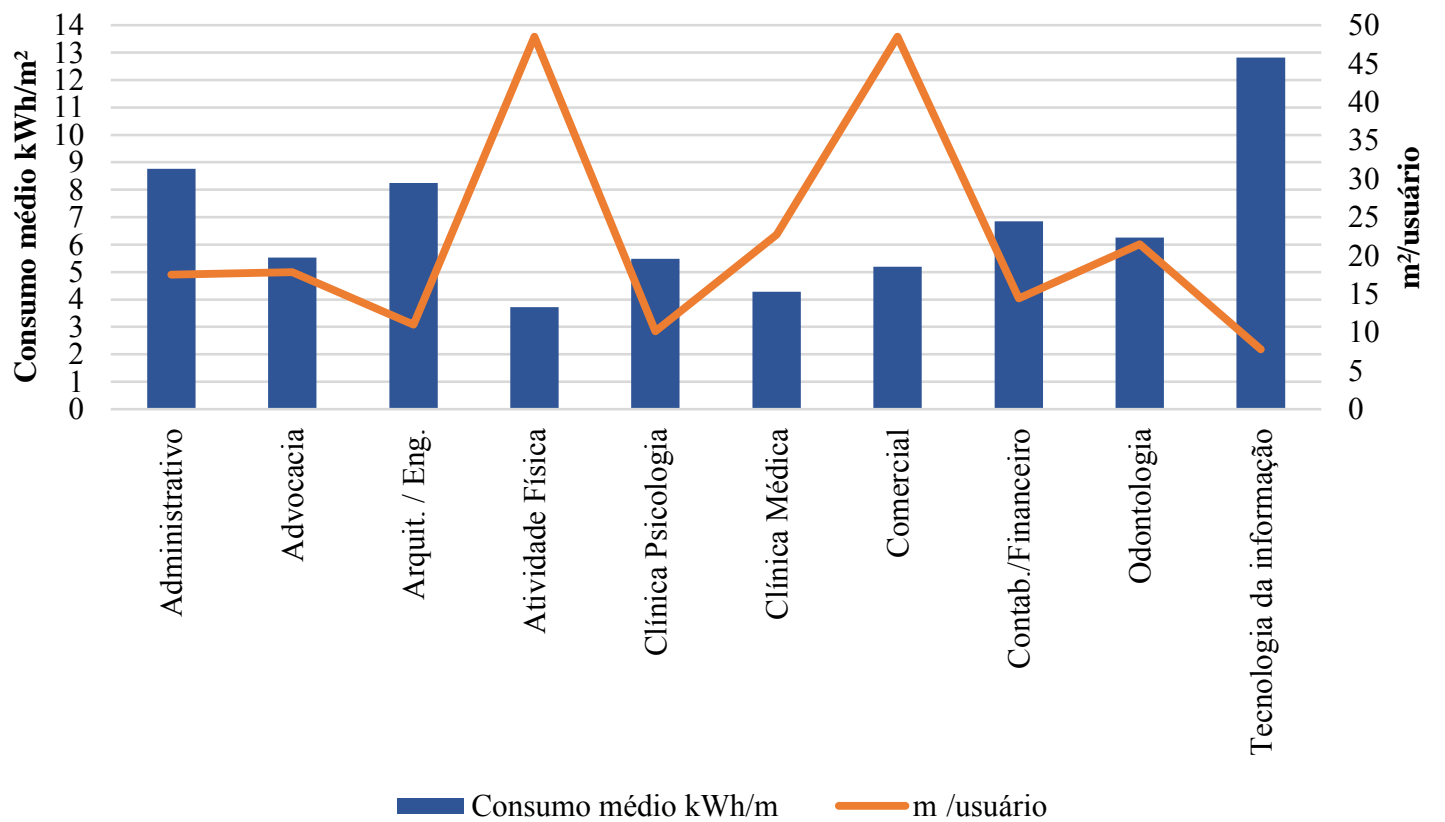

Nota: *o valor do $\mathrm{m}^{2}$ /usuário menor representa que há maior quantidade de usuários em um menor espaço; e **consumo médio dos meses de outubro, novembro e dezembro de 2019. 
Mesmo diante da variabilidade das atividades laborais levantadas, do consumo de energia e da taxa de ocupação, foi possível identificar padrões homogêneos quanto aos horários e ao período de ocupação. A Figura 5 indica a quantidade de usuários no edifício ao longo de um dia útil. Os usuários ocupam o edifício predominantemente das $8 \mathrm{~h}$ às $12 \mathrm{~h}$ e das $13 \mathrm{~h} 30 \mathrm{~min}$ às $18 \mathrm{~h}$, com picos de ocupação das $9 \mathrm{~h} 30 \mathrm{~min}$ às $11 \mathrm{~h}$ no período matutino e das $14 \mathrm{~h} 30 \mathrm{~min}$ às $17 \mathrm{~h}$ no período vespertino. Desse modo, a ocupação se concentra das $8 \mathrm{~h}$ às 18h, assim como é estipulado pela INI-C (INSTITUTO..., 2021), uma programação com a permanência de $10 \mathrm{~h}$ diárias no edifício. Contudo, foi identificado que apenas $18 \%$ dos usuários permanecem na edificação por $10 \mathrm{~h}$, sendo a ocupação com $8 \mathrm{~h}$ de permanência a mais representativa, relativa a $23 \%$ dos usuários.

\section{Definição dos clusters e padrões de uso e operação dos sistemas}

Para sistematizar e compreender os diferentes perfis de operação dos sistemas presentes no edifício comercial em análise, adotou-se o agrupamento alcançado na sexta hipótese com a seleção de 55 variáveis e a formação de cinco clusters. O número de usuários representativos para cada grupo foi variável, sendo $\mathrm{C} 1$ com $21 \%$ dos usuários entrevistados, $\mathrm{C} 2$ com $6 \%, \mathrm{C} 3$ com $17 \%, \mathrm{C} 4$ com $40 \%$ e $\mathrm{C} 5$ com $16 \%$ dos usuários.

As variáveis referentes às ações dos usuários nos sistemas de janelas e persianas apresentaram maior significância para a distribuição dos clusters e maior diversidade na operação. Já o sistema de iluminação artificial teve a menor variação na operação entre os grupos, apresentando atitudes similares. Consoante com as pesquisas de Yun, Kim e Kim (2012), Leite e Gutierrez (2016) e Gunay et al. (2017), foi identificado na literatura que o comportamento dos usuários na operação do sistema de iluminação artificial é semelhante, independentemente da região e do clima. No entanto, conforme as pesquisas de Vecchi et al. (2017), Langevin, Gurian e Wen (2015), D’Oca et al. (2018), Brugnera, Roriz e Chvatal (2013), Pisello et al. (2016), Pan et al. (2018) e Bavaresco e Ghisi (2018), a operação de janelas, persianas e ar-condicionado apresentou divergências, considerando que tais pesquisas foram realizadas sobretudo em climas diferentes.

O diagrama de perfil dos cincos clusters com os dados normalizados, delineado na Figura 6, confirma a variação existente entre os grupos quanto à frequência de operação nos sistemas de janela, persiana e arcondicionado. Porém, demonstra a homogeneidade da ocupação e a similaridade na operação da iluminação artificial entre os cinco grupos. Por meio desse diagrama, é possível observar os fatores que se assemelham ou divergem entre os grupos, contribuindo na descrição dos clusters. Dessa forma, as características dos grupos são sintetizadas na forma como se relacionam com os quatro sistemas abordados neste estudo:

(a) cluster 1: usuários que interagem apenas com a iluminação artificial e o ar-condicionado. Mesmo com a possibilidade de operar janelas e persianas, fazem uso constante do condicionamento artificial;

(b) cluster 2: usuários em ambientes com ausência de janelas. Assim, operam a iluminação artificial e o arcondicionado. Contudo, não fazem uso constante do condicionamento artificial;

(c) cluster 3: usuários que operam persianas, iluminação artificial e ar-condicionado, mas não utilizam a ventilação natural;

(d) cluster 4: usuários que interagem com os quatro sistemas investigados, possuem preferência pela ventilação natural. E alguns usuários deste grupo aproveitam a iluminação natural; e

(e) cluster 5: usuários que interagem com as janelas, a iluminação artificial e o ar-condicionado. As persianas permanecem sempre abertas, e os usuários apresentam preferência pela ventilação natural.

Figura 5 - Padrão de ocupação no edifício analisado em um dia útil

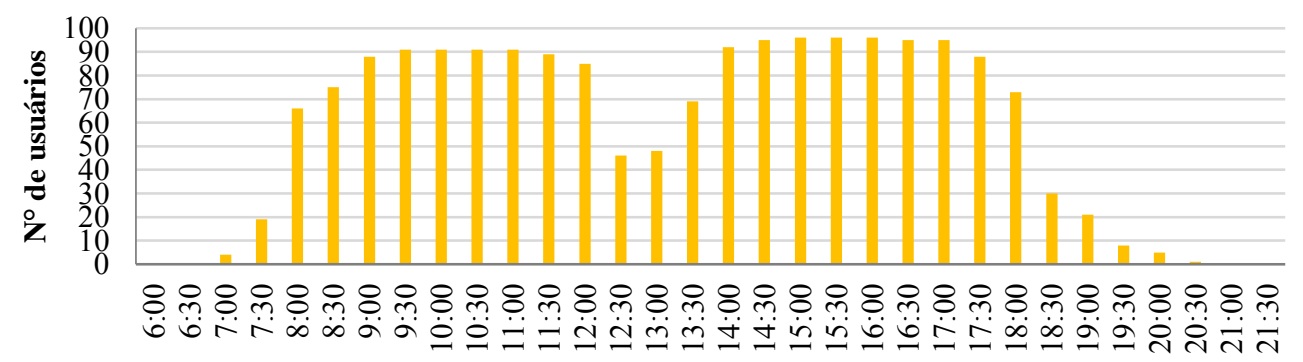

Horários 
Figura 6 - Diagrama de perfil dos clusters mediante os fatores do driver usuários

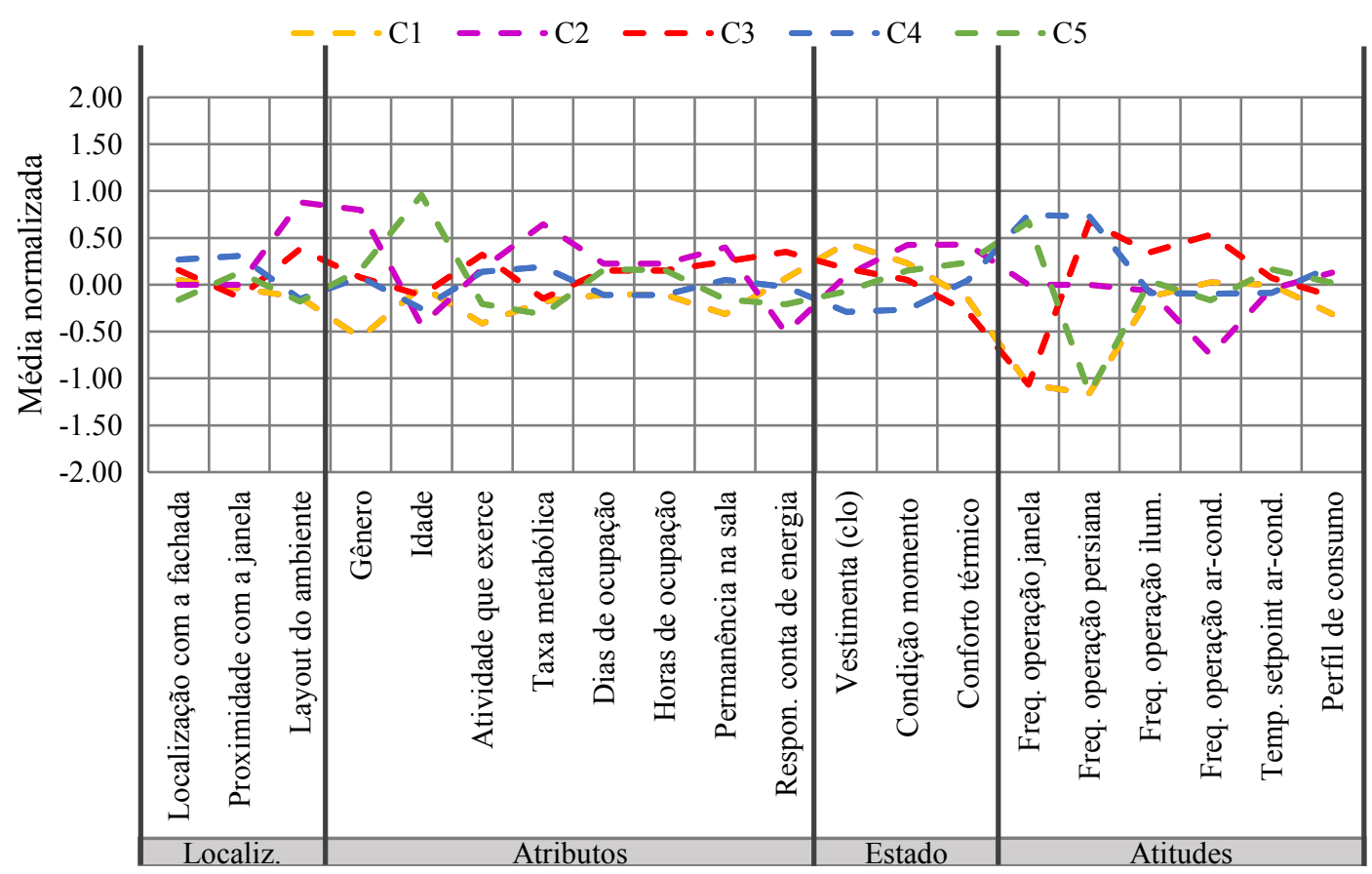

Comparando a localização dos usuários, na Figura 6, verifica-se que há uma diferenciação significativa no fator layout do cluster C2, visto que estes usuários estão em ambientes privados. Quanto à localização e à proximidade das janelas, apesar de não apresentarem grande variabilidade como a frequência de operação dos sistemas, os usuários do C3 estão mais próximos das janelas e o C4 apresenta o maior número de usuários distantes das janelas. No entanto, as variações das salas comerciais não apresentaram vínculo com os clusters. Com relação aos atributos, os clusters C1, C2 e C5 se destacam quanto aos fatores de gênero e idade, sendo essas características consideráveis para defini-los.

Complementam-se as características observadas na Figura 6 e os fatores predominantes nas atitudes de cada cluster por meio da frequência absoluta das variáveis, conforme a tabela de referência cruzada associada ao teste $\mathrm{z}$, disposta na Figura 7.

A Figura 7 indica a representatividade dos fatores relacionados às atitudes dos usuários nos grupos. Quanto mais elevado o percentual, maior é a sua representatividade. E, por meio da denotação de letras, confirmamse estatisticamente os clusters que se assemelham ou diferem diante de um mesmo fator. Na tabela identifica-se que os clusters $\mathrm{C} 1$ e C3 apresentam preferência pelo condicionamento artificial, $62 \%$ do $\mathrm{C} 1$ e $71 \%$ do C3 ligam o ar-condicionado no momento de chegada. Contrariamente, os clusters C4 e C5 preferem a ventilação natural, $78 \%$ do C4 e $69 \%$ do C5 abrem as janelas no momento de chegada; e janelas são fechadas predominantemente por desconforto acústico, fato citado por $78 \%$ do $\mathrm{C} 4$ e por $63 \%$ do C5.

$\mathrm{O}$ padrão de uso identificado no cluster $\mathrm{C} 1$ refere-se ao grupo de usuários que utilizam somente o condicionamento artificial e a iluminação artificial. Utilizam, predominantemente, salas de layout aberto e estão sob influência da orientação solar sul. No grupo, $57 \%$ dos usuários asseguram a preferência pelo uso do ar-condicionado; no entanto, o ruído externo também é um fator que interfere nessa decisão. Apesar de ser o grupo com a maior resistência térmica na vestimenta, apenas $14 \%$ a têm como limitante. Assim, o uso do condicionamento artificial se destaca como uma preferência pessoal. São inativos no manuseio das persianas, as quais permanecem fechadas ou abertas na maior parte do ano. Quanto à iluminação artificial, acionam predominantemente quando chegam no ambiente e só desligam quando saem no fim do dia. Contudo, $43 \%$ dos usuários deste grupo têm atitude de desligar nos períodos de ausência. A Figura 8 representa as características e os fatores predominantes envolvidos no uso de energia do cluster $\mathrm{C} 1$. 
Figura 7 - Fatores de influência nas atitudes e no comportamento dos clusters

\begin{tabular}{|c|c|c|c|c|c|c|}
\hline & Fatores & C1 & $\mathrm{C} 2$ & C3 & C4 & C5 \\
\hline \multirow{14}{*}{ 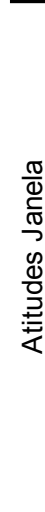 } & Sempre opera & $\bar{a}$ & $\mathrm{ab}$ & $\bar{a}$ & $50 \%$ b & $44 \% \mathrm{~b}$ \\
\hline & Às vezes opera & $a$ & $a b$ & $a$ & $50 \%$ b & $56 \% \mathrm{~b}$ \\
\hline & Nunca opera & $100 \%$ a & $\mathrm{b}$ & $100 \%$ a & $\mathrm{b}$ & $\mathrm{b}$ \\
\hline & Preferência pela ventilação natural & $a$ & $a b$ & $a$ & $53 \% \mathrm{~b}$ & $63 \% \mathrm{~b}$ \\
\hline & Preferência pelo condicionamento & $57 \%$ a & $a b$ & $47 \%$ a & $33 \% \mathrm{~b}$ & $12 \% \mathrm{~b}$ \\
\hline & Maior aceitabilidade térmica $\mathrm{p} /$ o calor & $a$ & $\mathrm{ab}$ & $a$ & $58 \% \mathrm{~b}$ & $57 \%$ b \\
\hline & Baixa aceitabilidade térmica $\mathrm{p} /$ o calor & $a$ & $a b$ & $a$ & $40 \% \mathrm{~b}$ & $43 \% \mathrm{~b}$ \\
\hline & Opera no momento de chegada & $\mathrm{a}$ & $\mathrm{a}$ & $\mathrm{a}$ & $78 \% \mathrm{~b}$ & $69 \%$ b \\
\hline & Opera pela qualidade do ar interno & $a$ & $a$ & $a$ & $90 \% \mathrm{~b}$ & $100 \% \mathrm{~b}$ \\
\hline & Opera por hábito e rotina & $a$ & $a b$ & $a$ & $48 \%$ bc & $69 \% \mathrm{c}$ \\
\hline & Fecha por ruído externo & $a$ & $a b$ & $a$ & $78 \% \mathrm{c}$ & $63 \% \mathrm{bc}$ \\
\hline & Fecha por ocorrência de chuva & $a$ & $a$ & $\mathrm{a}$ & $68 \% \mathrm{~b}$ & $75 \%$ b \\
\hline & Não opera por ruído externo & $43 \% a b$ & $\mathrm{bc}$ & $71 \%$ a & $\mathrm{C}$ & $\mathrm{C}$ \\
\hline & Não opera por causa da vestimenta & $14 \%$ a & $\mathrm{a}$ & $12 \%$ a & $\mathrm{a}$ & $a$ \\
\hline \multirow{17}{*}{ 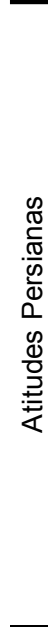 } & Sempre opera & $a$ & $a b$ & $65 \%$ bc & $70 \% \mathrm{c}$ & $a$ \\
\hline & Às vezes opera & $\mathrm{a}$ & $a b$ & $35 \% \mathrm{~b}$ & $30 \% a b$ & $a b$ \\
\hline & Nunca opera & $100 \%$ a & $\mathrm{b}$ & $\mathrm{b}$ & $\mathrm{b}$ & $100 \%$ a \\
\hline & Opera para controle da ilum. natural & $\mathrm{a}$ & $a$ & $88 \%$ b & $80 \%$ b & $a$ \\
\hline & Opera por hábito e rotina & $a$ & $a b c$ & $35 \% \mathrm{bc}$ & $43 \% \mathrm{c}$ & $a b$ \\
\hline & Opera para ter vista do exterior & $a$ & $\mathrm{ab}$ & $71 \% \mathrm{c}$ & $48 \%$ bc & $a$ \\
\hline & Opera no momento de chegada & a & $\mathrm{a}$ & $29 \%$ ab & $63 \% \mathrm{~b}$ & $a$ \\
\hline & Opera para ter iluminação natural & $a$ & $a b$ & $65 \%$ bc & $85 \% \mathrm{c}$ & $a$ \\
\hline & Opera por desconforto visual & $a$ & $a$ & $94 \% \mathrm{~b}$ & $85 \% \mathrm{~b}$ & $a$ \\
\hline & Opera por desconforto térmico & $a$ & $a b$ & $53 \%$ bc & $63 \% \mathrm{c}$ & $\mathrm{a}$ \\
\hline & Opera no momento de saída & $\mathrm{a}$ & $a b$ & $24 \% a b$ & $48 \% \mathrm{~b}$ & $\mathrm{a}$ \\
\hline & Não opera por hábito & $52 \%$ a & $a b c$ & $\mathrm{bc}$ & $\mathrm{c}$ & $19 \% \mathrm{ab}$ \\
\hline & Não opera por estar distante da janela & $19 \%$ a & $\mathrm{ab}$ & $a b$ & $\mathrm{~b}$ & $13 \% \mathrm{ab}$ \\
\hline & Não opera pois outros operam & $10 \% a b$ & $a b$ & $a b$ & $\mathrm{~b}$ & $25 \%$ a \\
\hline & Preferência em não manusear & $14 \%$ a & $a$ & $a$ & $a$ & $13 \%$ a \\
\hline & Permanece sempre aberta & $43 \% a b$ & $\mathrm{bc}$ & $\mathrm{C}$ & $\mathrm{c}$ & $81 \%$ a \\
\hline & Permanece sempre fechada & $52 \%$ a & $a b c$ & $\mathrm{bc}$ & $\mathrm{C}$ & $19 \% a b$ \\
\hline \multirow{11}{*}{ 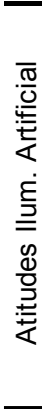 } & Sempre opera & $86 \%$ a & $100 \%$ a & $100 \% a$ & $82 \%$ a & $93 \%$ a \\
\hline & Às vezes opera & $10 \% a$ & $a$ & $\mathrm{a}$ & $18 \%$ a & $7 \% a$ \\
\hline & Nunca opera & $5 \%$ a & $\mathrm{a}$ & $\mathrm{a}$ & $\mathrm{a}$ & $\mathrm{a}$ \\
\hline & Preferência pela iluminação artificial & $29 \%$ a & $a$ & $29 \%$ a & $20 \%$ a & $25 \%$ a \\
\hline & Opera por conforto visual & $81 \%$ a & $100 \% \mathrm{a}$ & $88 \%$ a & $93 \%$ a & $94 \%$ a \\
\hline & Opera por hábito e rotina & $43 \% \mathrm{a}$ & $17 \%$ a & $47 \%$ a & $50 \%$ a & $75 \%$ a \\
\hline & Opera por necessidade de alta ilumin. & $24 \%$ a & $50 \%$ a & $29 \%$ a & $23 \%$ a & $12 \%$ a \\
\hline & Opera no momento de chegada & $76 \%$ a & $100 \%$ a & $100 \% a$ & $78 \%$ a & $76 \%$ a \\
\hline & Plano de trabalho não é iluminado & $29 \%$ a & $100 \% a$ & $29 \%$ a & $25 \%$ a & $19 \%$ a \\
\hline & Desliga quando ausente & $43 \%$ a & $33 \%$ a & $59 \%$ a & $73 \%$ a & $56 \%$ a \\
\hline & Aproveitamento da iluminação natural & $10 \% a$ & $\mathrm{a}$ & $\mathrm{a}$ & $33 \%$ a & $19 \%$ a \\
\hline \multirow{13}{*}{ 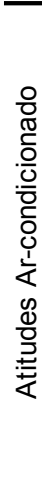 } & Sempre opera & $76 \% a b$ & $17 \% \mathrm{~b}$ & $94 \%$ a & $60 \% \mathrm{ab}$ & $63 \% a b$ \\
\hline & Às vezes opera & $14 \%$ a & $50 \%$ a & $6 \%$ a & $40 \%$ a & $31 \%$ a \\
\hline & Nunca opera & $10 \%$ a & $33 \%$ a & $a$ & $a$ & $6 \% \mathrm{a}$ \\
\hline & Opera por conforto térmico & $100 \% a b$ & $67 \%$ b & $94 \% a b$ & $100 \% a$ & $94 \% a b$ \\
\hline & Opera por causa da vestimenta & $14 \%$ a & $\mathrm{a}$ & $6 \%$ a & $a$ & $\mathrm{a}$ \\
\hline & Opera por necessidade da atividade & $5 \%$ a & $17 \%$ a & $29 \%$ a & $15 \%$ a & $12 \%$ a \\
\hline & Opera por hábito e rotina & $57 \%$ a & $17 \%$ a & $59 \%$ a & $48 \%$ a & $50 \%$ a \\
\hline & Opera no momento de chegada & $62 \%$ a & $33 \% a b$ & $71 \%$ a & $23 \% b$ & $31 \% a b$ \\
\hline & Opera por pouco desconfoto térmico & $71 \% a b$ & $\mathrm{c}$ & $82 \%$ b & $38 \%$ ac & $44 \%$ abc \\
\hline & Opera quando muito desconforto & $14 \%$ a & $67 \% a b$ & $12 \%$ a & $60 \% \mathrm{~b}$ & $50 \% a b$ \\
\hline & Opera por solicitação de colegas & $38 \%$ a & $33 \% \mathrm{ab}$ & $35 \%$ a & $75 \% \mathrm{~b}$ & $62 \% a b$ \\
\hline & Opera por atender clientes/pacientes & $48 \%$ a & $50 \%$ a & $71 \%$ a & $60 \%$ a & $38 \%$ a \\
\hline & Desliga quando ausente & $43 \%$ a & $33 \%$ a & $59 \%$ a & $68 \%$ a & $81 \%$ a \\
\hline
\end{tabular}

Nota: (1) Clusters com letras iguais para a mesma variável não apresentam diferenças entre as porcentagens e clusters com letras diferentes para a mesma variável apresentam diferenças entre as porcentagens. (2) Os espaços vazios ocorrem em razão de os fatores terem sido analisados separadamente para os grupos que operam e não operam os sistemas, ou ainda, representam ausência do sistema, no caso do cluster C2. (3) Como todos os usuários desligam a iluminação e o ar-condicionado no momento de saída no fim do dia, foi analisado o comportamento de desligar esses sistemas apenas em períodos de ausência, como em horário de almoço ou quando saem para alguma atividade externa. 
Figura 8 - Características e fatores predominantes no padrão de uso do cluster C1

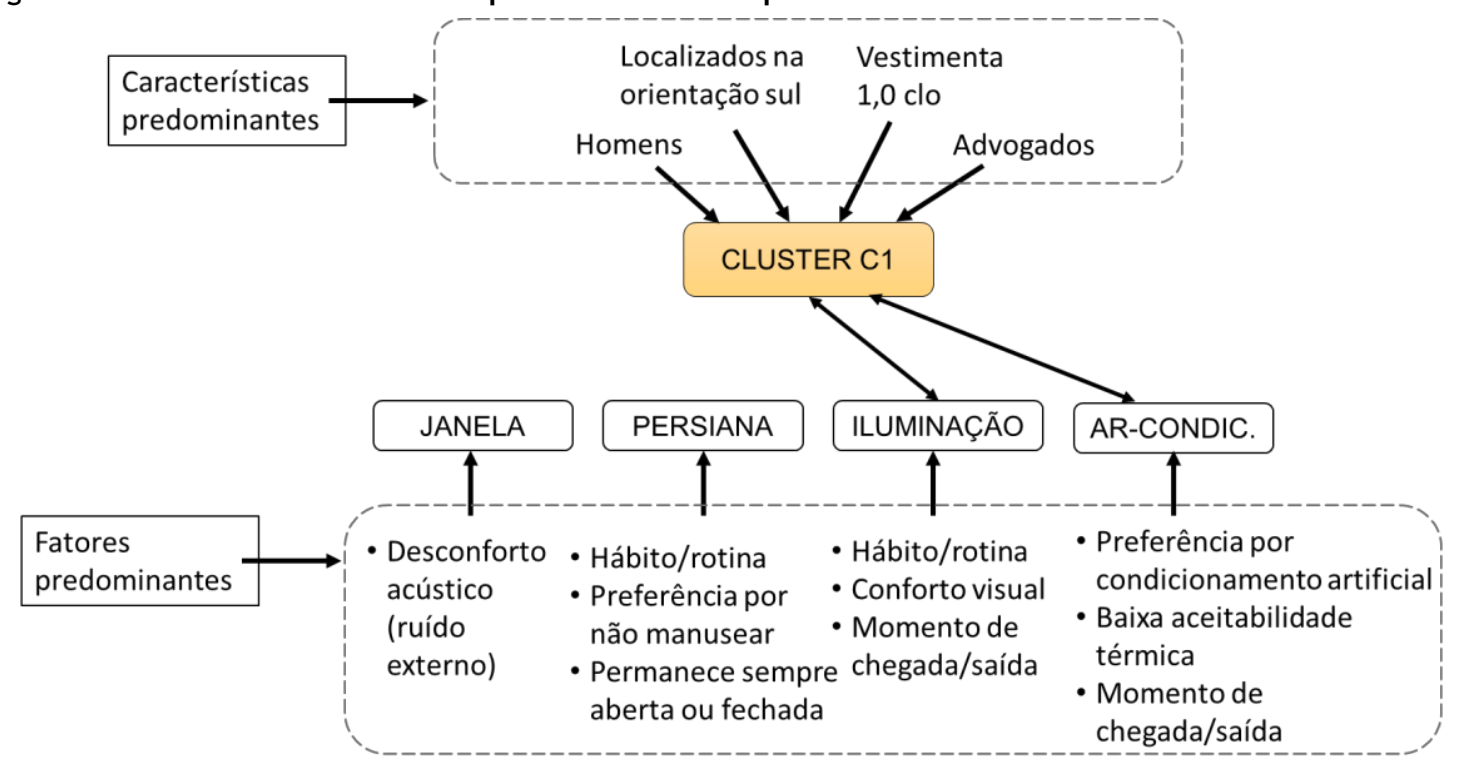

O padrão de uso do cluster C2, esquematizado na Figura 9, é decorrente da ausência de janelas no ambiente em que trabalha e do layout privado das salas. Por consequência, tem a necessidade de utilizar a iluminação artificial durante todo o período de trabalho. Apesar da ausência da ventilação natural, 67\% do grupo utiliza o condicionamento apenas em momentos necessários de muito desconforto, não constituindo uma preferência ao uso constante.

Usuários do cluster C3 não fazem uso da ventilação natural, determinado, principalmente, devido ao ruído externo apontado como limitante para $71 \%$ do grupo. As persianas são controladas em $94 \%$ dos casos por desconforto visual, além do objetivo de $71 \%$ terem visibilidade para o exterior e de $88 \%$ apreciarem a iluminação natural. No entanto, mesmo sendo ativos na operação das persianas, não fazem o aproveitamento da iluminação natural quando em condições satisfatórias de iluminância. Além disso, estão majoritariamente em salas com layouts privados e recebem notável influência da fachada leste. A Figura 10 sistematiza a interação do cluster $\mathrm{C} 3$ com os sistemas, compreendendo suas características e fatores predominantes.

Constituído pelo maior número de usuários, o cluster $\mathrm{C} 4$ diferencia-se por sua interação nos quatros sistemas investigados, apresenta localização diversificada com influência das orientações norte, sul e oeste, e está inserido principalmente em salas com layout aberto. A abertura das janelas é motivada, especialmente, para adquirir uma melhor qualidade do ar interno, com representatividade de $90 \%$ dos usuários, dos quais $78 \%$ possuem o costume de abri-las no momento de chegada. Ademais, parte do grupo expressa preferência pela ventilação natural, originando um hábito de operar as janelas. No entanto, o ruído externo e o alto desconforto térmico são os principais fatores que os motivam a fechar as janelas ao longo do dia. Quanto às persianas, os usuários abrem frequentemente para usufruir da iluminação natural, $63 \%$ têm o comportamento de abrir no momento de chegada e $85 \%$ de fechar ao longo do dia quando sentem desconforto visual. Não apresentam comportamento de fechar as persianas quando saem do local de trabalho, as quais são operadas novamente apenas no dia seguinte, conforme a necessidade. O padrão de uso do cluster C4 encontra-se estruturado na Figura 11.

Com relação ao cluster C5, há similaridades comportamentais na operação das janelas com os usuários do cluster C4, que são unânimes em abrir as janelas para obter qualidade do ar interno. Além disso, prevalecem o layout aberto e a proximidade com as orientações norte e sul. No entanto, o C5 possui preferência e uso da ventilação natural mais significativos: $69 \%$ do grupo possui o comportamento de abertura das janelas no momento de chegada. Entretanto, como nos demais grupos, o desconforto acústico é um fator que prejudica o aproveitamento da ventilação natural de $63 \%$ do grupo. Assim, o condicionamento artificial é usado com o intuito de obter conforto ou quando outros usuários solicitam. Quanto às persianas, não possui a atitude de manuseá-las, pois não sente necessidade de fechá-las. Independentemente de as aberturas proporcionarem iluminação natural satisfatória, $76 \%$ dos usuários utilizam a artificial desde o momento de chegada, comportamento motivado pelo hábito. Na Figura 12 podem ser observados as características e os fatores envolvidos na interação do cluster C5 com os sistemas. 
Figura 9 - Características e fatores predominantes no padrão de uso do cluster C2

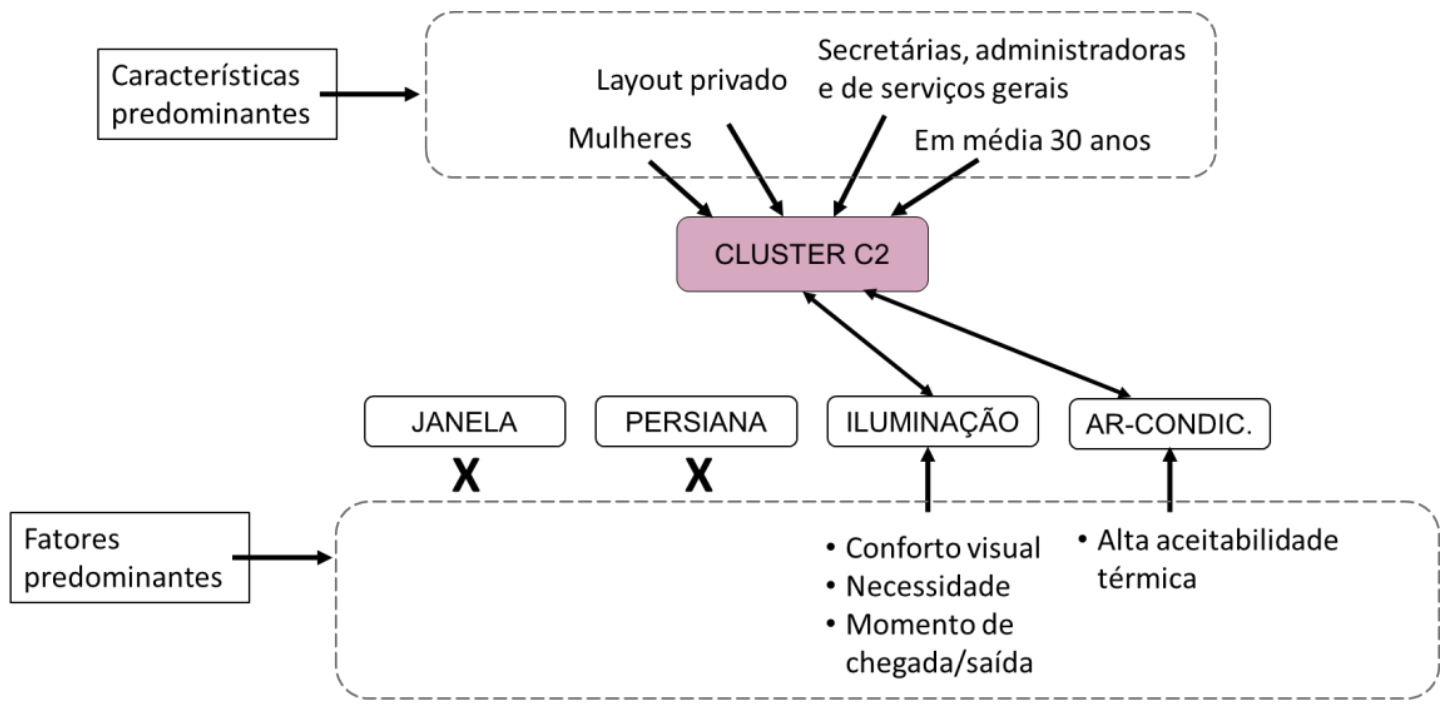

Figura 10 - Características e fatores predominantes no padrão de uso do cluster C3

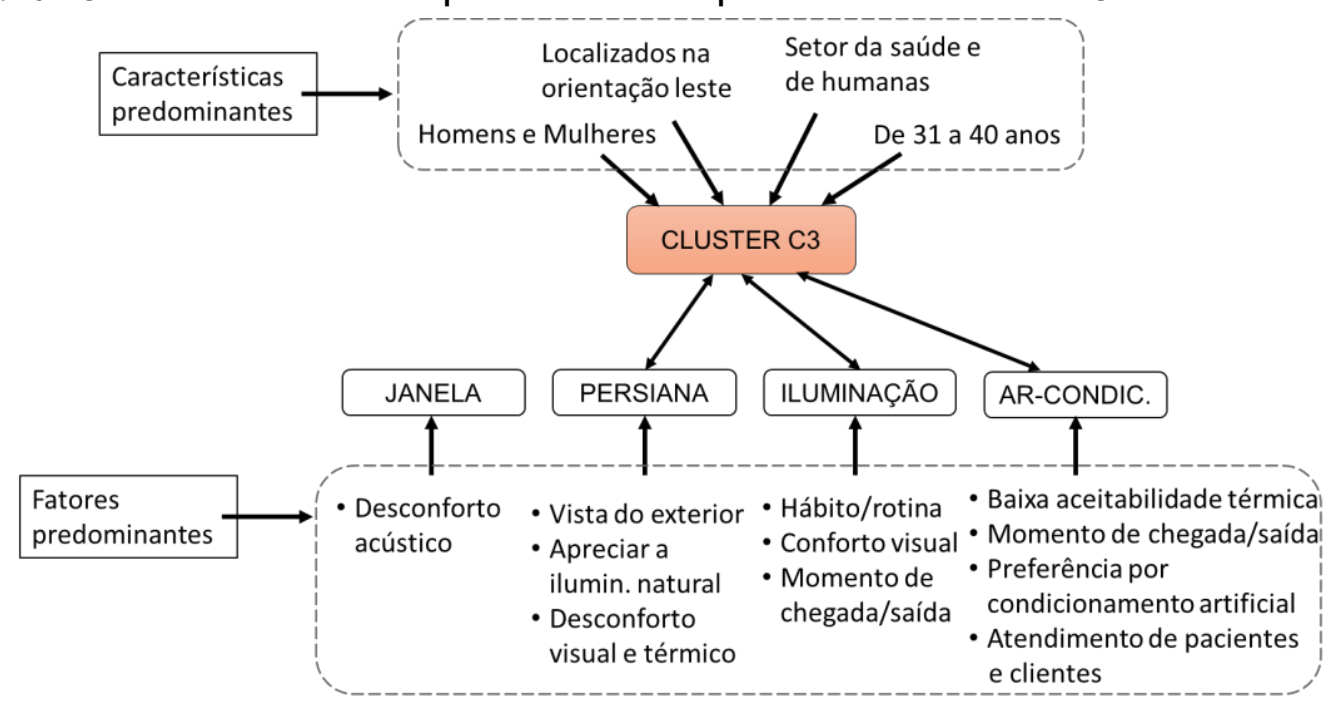

Figura 11 - Características e fatores predominantes no padrão de uso do cluster C4

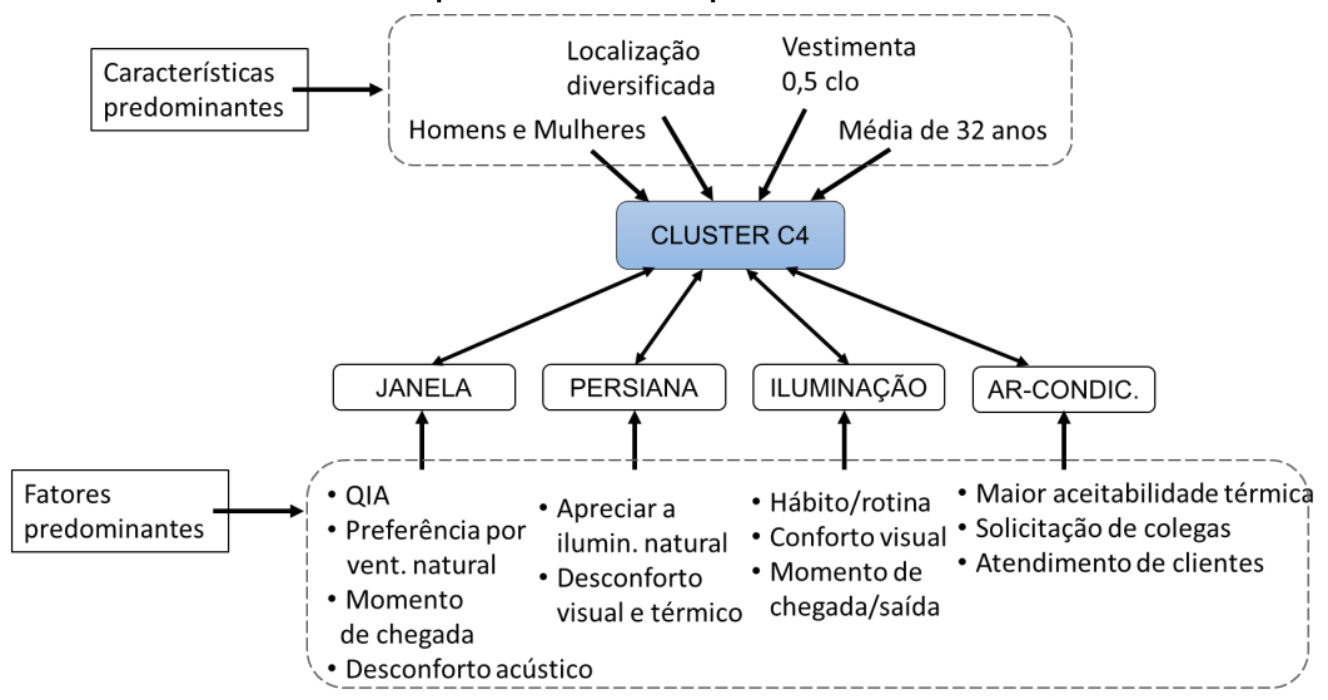


Figura 12 - Características e fatores predominantes no padrão de uso do cluster C5

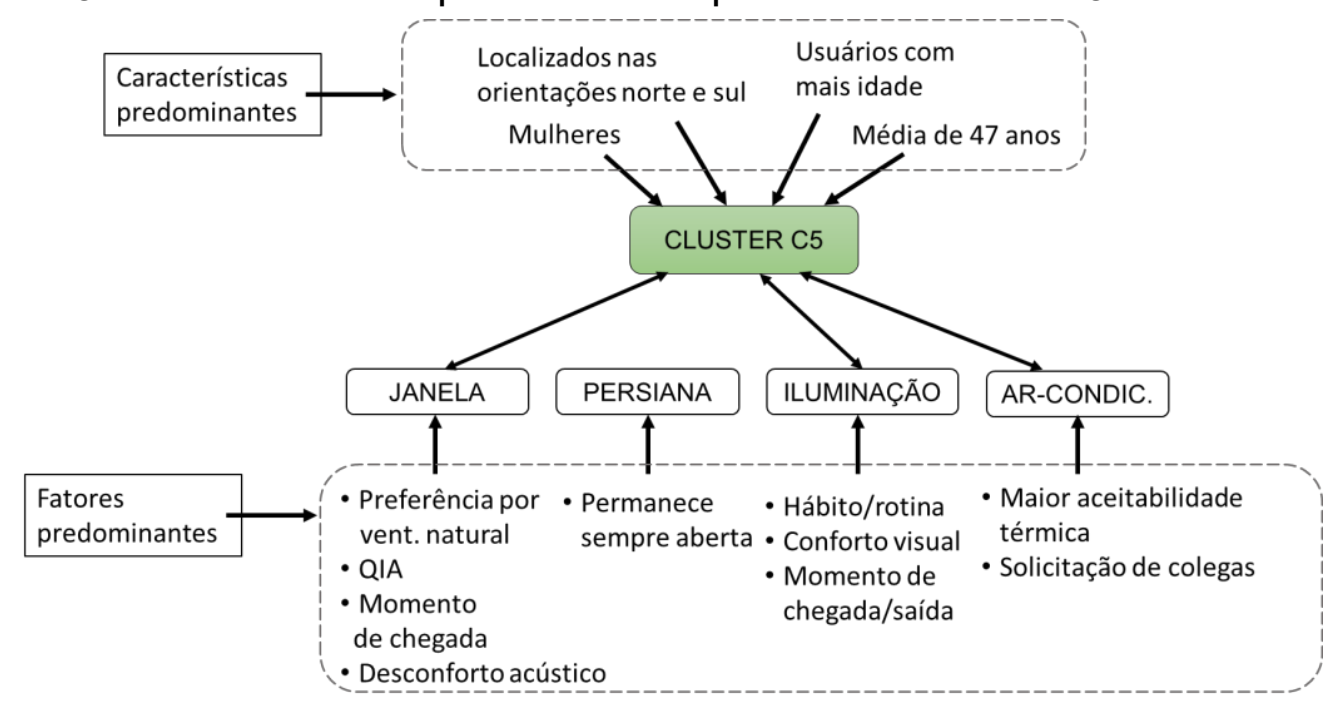

Indiscutivelmente, a iluminação artificial é utilizada por todos os grupos de forma similar e influenciada pelos mesmos fatores. $\mathrm{Na}$ literatura, as pesquisas são unânimes em constatar que a iluminação artificial é usada com frequência durante toda a ocupação e que não há vínculo com a iluminação natural (YUN; KIM; KIM, 2012; LEITE; GUTIERREZ, 2016; GUNAY et al., 2017). Contudo, os resultados dos padrões de uso não apresentaram uma preferência dos usuários pelo uso da iluminação artificial, sugestionando-se que a atitude de uso constante seja um hábito influenciado pelo conforto visual para o trabalho.

De forma semelhante, os equipamentos de ar-condicionado são utilizados por todos os grupos; contudo, é possível observar diferenças nos fatores de influência e na frequência com que operam o sistema. Os clusters C1 e C3 apresentam uso constante do condicionamento artificial, sendo, na maioria dos casos, utilizado desde o momento de chegada no ambiente. No entanto, os usuários dos clusters C2, C4 e C5 demonstraram maior aceitabilidade térmica, utilizando o condicionamento artificial em condições de desconforto térmico do próprio usuário ou dos demais colegas. Além disso, os clusters C4 e C5 apresentaram preferência pela ventilação natural, com o hábito de abrir as janelas no período da manhã - momento de chegada - para obter melhor qualidade do ar interno. Porém, como já citado, o desconforto acústico causado pelo ruído externo força-os a adotarem o condicionamento artificial.

A interação dos usuários nos sistemas de janelas e ar-condicionado apresentou padrões diferenciados; no entanto, foi observado durante as entrevistas e os relatos dos usuários a mesma percepção dos autores Brugnera, Roriz e Chvatal (2013) em São Carlos, São Paulo, em que o ar-condicionado tende a permanecer ligado até o momento de saída do ambiente.

Para o verão, as pesquisas de Pan et al. (2018) em Pequim, na China, de D’Oca et al. (2018) em Turim, Perugia e Rende, na Itália, e Sun et al. (2018) em Harbin, na China, identificaram que o padrão comportamental prevalecente utiliza a ventilação natural, sendo as janelas abertas no momento de chegada e ligado o ar-condicionado quando em desconforto térmico. No entanto, Vecchi et al. (2017), com análises em Florianópolis, de clima mais quente, identificaram que o uso do condicionamento artificial era constante no período de verão. Apesar de os resultados comportamentais serem similares aos das pesquisas citadas, não há um padrão de uso único a ser priorizado. Dessa forma, generalizações podem omitir as atitudes de um grupo de usuários com comportamentos distintos, refletindo em uma estimativa inadequada do consumo real de energia elétrica. Em relação às persianas, os autores Haldi e Robinson (2010) verificaram que o padrão de uso ocorre com maior frequência no momento de chegada, semelhante ao identificado no cluster C4. Contudo, observa-se que a operação das persianas pelo cluster C3 não ocorre no momento de chegada. Além disso, foi obtida nos resultados dos clusters $\mathrm{C} 1$ e C3 a ausência de interação com as persianas, da mesma forma que Bavaresco e Ghisi (2018) identificaram, porém os referidos autores separaram os grupos de usuários com persianas abertas constantemente daqueles que permanecem com a persiana fechada.

A Figura 13 apresenta o estado dos sistemas durante a ocupação ao longo do dia para os cinco padrões de uso. É possível obter, aproximadamente dentro de um intervalo, a porcentagem de uso dos sistemas e verificar a dinâmica de operação nos quatro sistemas investigados. Por exemplo, notam-se a abertura das 
janelas pelos usuários dos clusters C4 e C5 no início da manhã, com o fechamento ao longo do dia, e o acionamento do ar-condicionado. Já o C3 apresenta ausência na operação das janelas e acionamento dos equipamentos de ar-condicionado. Diante de tais fatos, prever nas simulações termoenergéticas o uso constante dos sistemas de iluminação durante o período de ocupação nos edifícios comerciais proporcionará resultados semelhantes ao real. Quanto à previsão do uso de janelas e de ar-condicionado, esses variam conforme a necessidade da atividade que cada usuário exerce. Recomenda-se que nas simulações termoenergéticas sejam programados os diversos comportamentos simultâneos dos grupos, considerando principalmente as várias tomadas de ações perante os fatores de conforto térmico e acústico, atividade que exerce, qualidade do ar interno, hábitos e preferências pessoais.

Figura 13 - Estados dos sistemas ao longo do dia para cada cluster
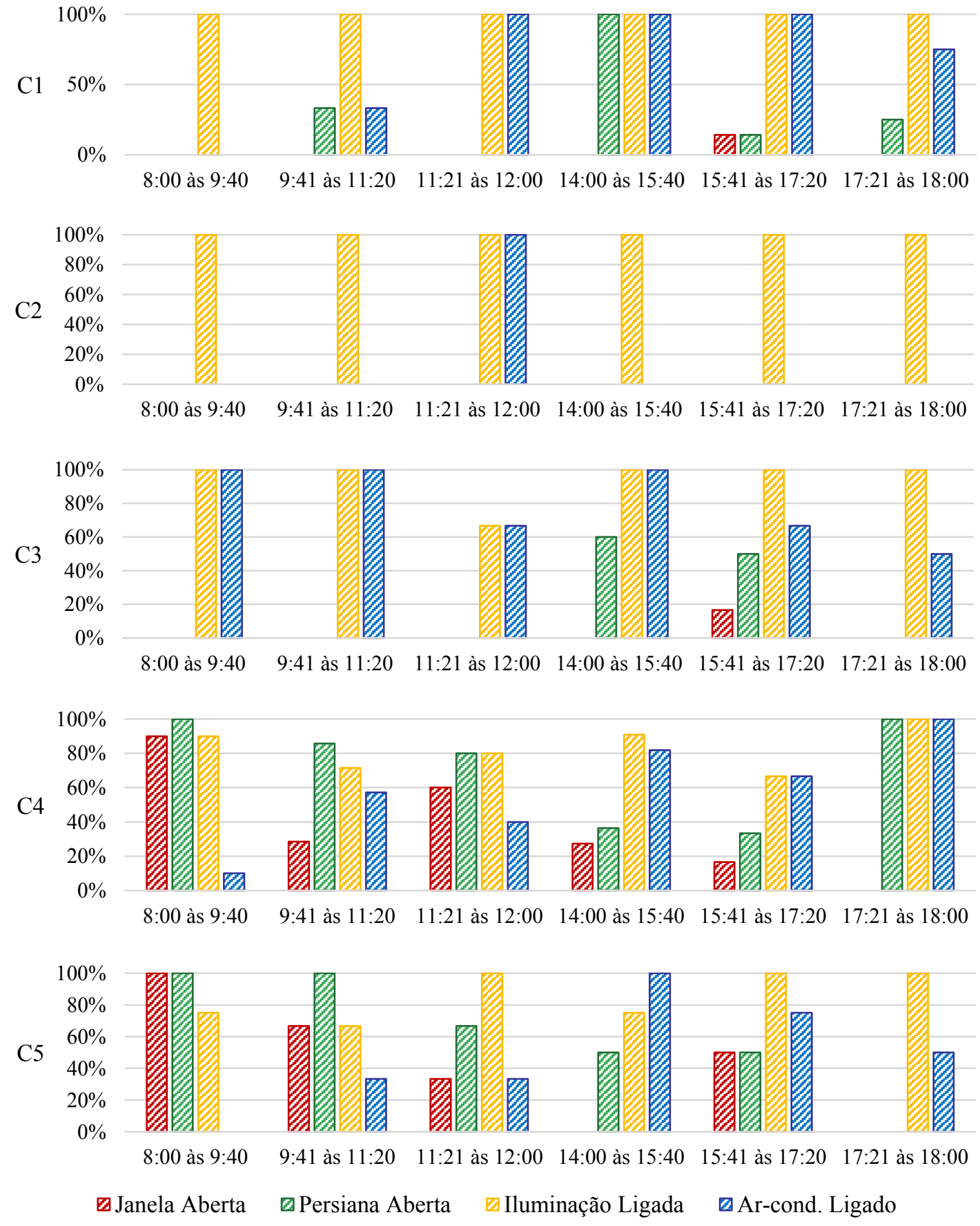


\section{Fatores influentes nos padrões de uso}

$\mathrm{Na}$ análise dos padrões de uso encontrados, constatou-se que, entre os 72 fatores investigados, 35 proporcionaram influências semelhantes entre os grupos e 37 influenciaram os grupos de modo diferente, ou seja, diante de um mesmo fator, apresentaram atitudes diferentes. A Tabela 2 sintetiza os fatores que interferiram em comportamentos distintos dos clusters.

$\mathrm{O}$ valor do qui-quadrado mais alto foi relacionado à localização dos usuários, indicando que esse fator diverge nos padrões de uso.

Constata-se a significância da orientação solar das salas, sendo os grupos de usuários localizados sob influência das orientações solares norte e sul os mais suscetíveis a adotar a ventilação natural, bem como dispor de quantidade maior de iluminação natural no ambiente sem ofuscamento. Com base nos dados levantados, é possível observar que os usuários expostos à fachada leste apresentaram frequência maior no uso do ar-condicionado. A Figura 14 revela que 92\% dos usuários entrevistados na face leste utilizam a climatização artificial em uma frequência $20 \%$ superior ao identificado nas demais fachadas, além de mostrarem maior assiduidade na operação das persianas. Observa-se na Figura 15 o predomínio de usuários do cluster $\mathrm{C} 3$, que não utilizam a ventilação natural, próximos da fachada leste. Tal dado evidencia a influência da pele de vidro - presente na fachada leste do edifício - nas ações comportamentais dos usuários.

Além disso, é interessante destacar que, mesmo em layouts abertos, a distância dos usuários perante as janelas e as persianas não os impede de adotar atitudes de interação para obter ventilação e iluminação natural, diferentemente do identificado pelos autores Leite e Gutierrez (2016) e Bavaresco e Ghisi (2018), para quem a falta de interação com as persianas crescia à medida que o usuário se distanciava da janela. Por outro lado, a baixa frequência na operação das persianas pelos usuários que estão localizados a sul e a maior assiduidade pelos que estão a leste e a oeste identificados na pesquisa são consoantes ao mencionado por Bavaresco e Ghisi (2018).

Tabela 2 - Fatores que apresentaram diferença entre os padrões de uso

\begin{tabular}{|c|c|c|c|c|}
\hline Categoria & Subcategoria & Fatores & Qui-quad. & p-valor \\
\hline \multirow{3}{*}{ Espaço } & \multirow{3}{*}{ Característica } & Área útil da sala & $15,316^{*}$ & 0,004 \\
\hline & & Consumo médio mensal & $15,198^{*}$ & 0,004 \\
\hline & & Orientação solar da fachada & $56,379 * *$ & 0,001 \\
\hline Cond. Amb. & Condição interna & Iluminância no plano de trabalho & $10,408^{*}$ & 0,34 \\
\hline \multirow{12}{*}{ Sistema } & \multirow{2}{*}{ Janela } & Existência do sistema & $100 * *$ & $<0,001$ \\
\hline & & Estado & $121,299 * *$ & $<0,001$ \\
\hline & \multirow{4}{*}{$\begin{array}{l}\text { Elementos internos } \\
\text { de sombreamento }\end{array}$} & Existência do sistema & $66,728 * *$ & $<0,001$ \\
\hline & & Estado & $72,186^{* *}$ & $<0,001$ \\
\hline & & Cor & $87,215^{* *}$ & $<0,001$ \\
\hline & & Material & $77,036^{* *}$ & $<0,001$ \\
\hline & \multirow{2}{*}{ Iluminação } & Estado & $15,754 * *$ & 0,046 \\
\hline & & Divisão de circuitos & $21,838 * *$ & $<0,001$ \\
\hline & \multirow{4}{*}{ Ar-condicionado } & Existência do sistema & $20,676^{* *}$ & $<0,001$ \\
\hline & & Estado & $27,933 * *$ & $<0,001$ \\
\hline & & Tipo do ar-condicionado & $32,929 * *$ & 0,001 \\
\hline & & Tipo de operação & $22,712 * *$ & 0,004 \\
\hline \multirow{5}{*}{ Usuário } & \multirow{2}{*}{ Localização } & Local. em relação à orientação solar & $106,931 * *$ & $<0,001$ \\
\hline & & Proximidade com a janela & $107,621 * *$ & $<0,001$ \\
\hline & \multirow{2}{*}{ Atributos } & Gênero & $11,364 * *$ & 0,023 \\
\hline & & Faixa etária (idade) & $17,079 *$ & 0,002 \\
\hline & Estado & Vestimenta & $34,083 * *$ & 0,005 \\
\hline
\end{tabular}

Nota: *valores obtidos no teste de Kruskal-Wallis. **valores obtidos no teste qui-quadrado. 1) As variáveis que resultaram em p-valor menor que 0,05 indicaram diferenças estatisticamente significativas, demonstrando, assim, associação com os padrões de uso. 2) Todos os fatores relacionados às atitudes dos usuários são significativos, com exceção das atitudes relacionadas à operação do sistema de iluminação artificial. 3) Quanto aos fatores das atitudes na operação da iluminação artificial, somente a condição de ausência de iluminação natural no plano de trabalho se mostrou influente. 
Figura 14 - Relação do fator de localização do usuário na frequência de operação dos sistemas

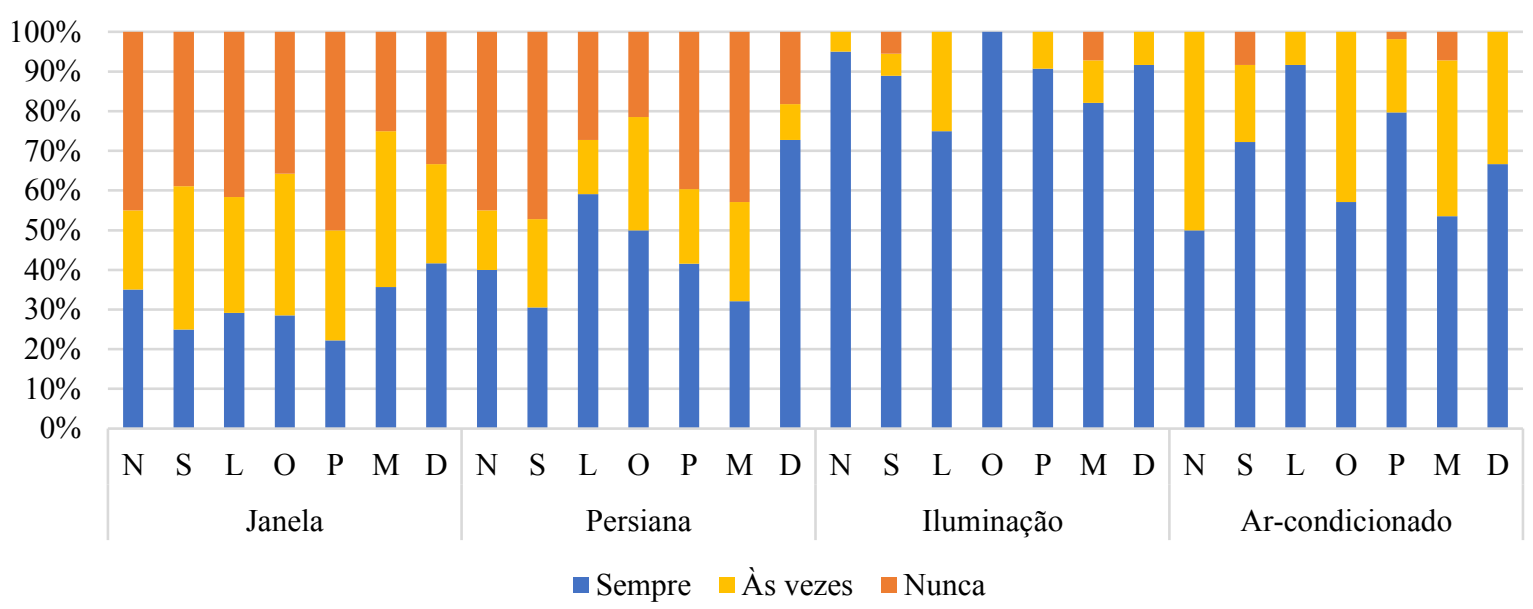

Nota: *localização do usuário com a orientação solar, em que $\mathrm{N}=$ norte, $\mathrm{S}=$ sul, $\mathrm{L}=$ leste e $\mathrm{O}=$ oeste. ${ }^{* *}$ proximidade do usuário com a janela, em que $\mathrm{P}=$ próximo, $M=$ mediano e $\mathrm{D}=$ distante.

Figura 15 - Localização de cada usuário conforme seu respectivo cluster

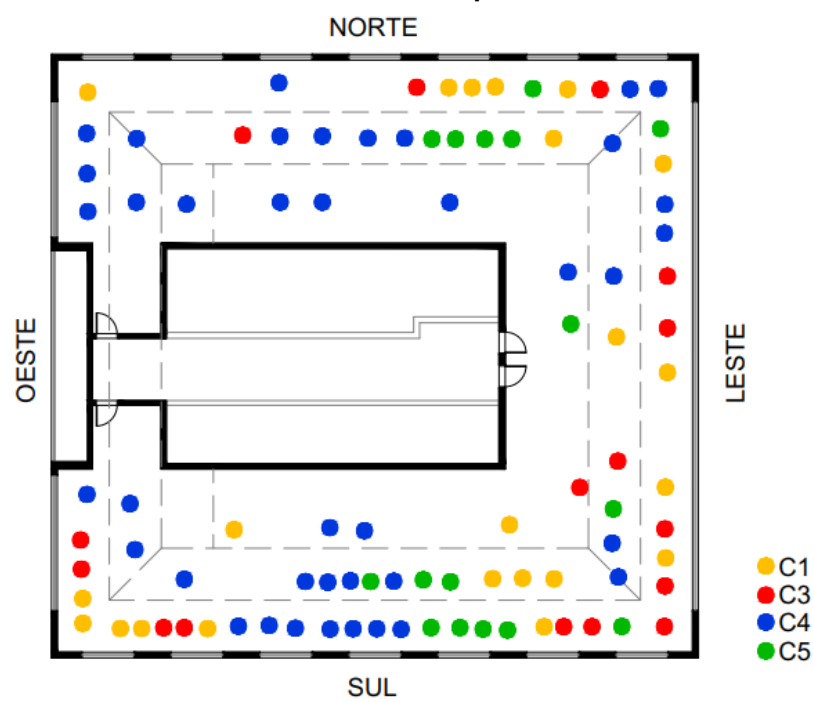

Nota: *usuários do cluster C2 estão em ambientes sem janelas e sem contato com a envoltória.

A iluminância adequada no plano de trabalho também se mostrou relevante com base no teste de KruskalWallis. Na pesquisa, $72 \%$ das salas comerciais analisadas não dispunham de acionamento separado para as luminárias próximas às janelas, sendo importante a divisão de circuitos para cada usuário controlar a iluminação no seu plano de trabalho. Complementa-se que $83 \%$ dos usuários possuem o hábito de acionar a iluminação artificial e $41 \%$ de ligar o ar-condicionado no momento de chegada, assim como a predisposição para não ajustarem os sistemas ao longo do dia, mesmo em condições climáticas agradáveis. Com isso, sugestiona-se adotar em projetos recursos automatizados, como a presença de dimerizadores nas luminárias para controle da iluminância.

Em relação ao consumo de energia, apesar da relevância de identificar os diferentes padrões de uso por impactarem no consumo de energia de forma diferente, na presente pesquisa não foi possível mensurar um valor típico de consumo de energia para cada padrão de uso, pois foram levantados os consumos totais das unidades e esses não representam as atitudes de um grupo específico. Contudo, mesmo não correlacionando diretamente o consumo com os agrupamentos, foi observado que usuários localizados na fachada com grande percentual de abertura, mesmo que esta seja eficiente, usam o ar-condicionado com maior frequência.

Em suma, os principais fatores identificados entre os padrões de uso que influenciaram as ações dos usuários foram o ruído, o ofuscamento, a carga de calor, a localização, hábitos e preferências pessoais. Enquanto 30\% 
dos usuários possuem o hábito de abrir as janelas, esse valor aumenta para 53\% com o hábito de usar o condicionamento artificial. Nesse sentido, além das propriedades termofísicas do edifício, das características das salas, das condições ambientais e da especificação dos sistemas, devem ser levados em consideração no comportamento do usuário os hábitos e as preferências individuais por influenciarem as diferentes tomadas de decisão.

Embora se tenha confirmado que, diante dos fatores ambientais e fisiológicos dos usuários, seja possível prever as ações dos usuários, perante os fatores psicológicos e sociais as suas atitudes são subjetivas.

\section{Conclusão}

Neste estudo, identificaram-se os padrões de uso em um edifício comercial mediante a análise de 72 fatores de influência nas ações dos usuários e a sinergia existente na operação dos sistemas de janelas, persianas, iluminação e ar-condicionado. Diante da grande heterogeneidade comportamental e da natureza das atividades laborais, foram constatados cinco padrões de uso que se diferem quanto à interação com os quatro sistemas abordados. No entanto, todos os agrupamentos apresentaram semelhanças quanto à operação no sistema de iluminação artificial.

Quanto à influência dos fatores explorados nos padrões de uso, o ruído externo e a alta radiação solar no interior dos ambientes foram os principais motivos que impediram os usuários de utilizarem a ventilação natural, principalmente para os próximos da fachada leste com grande área envidraçada, que permanecem com as persianas abaixadas e ar-condicionado ligado desde o momento de chegada no início da manhã. Além dos fatores ambientais, os psicológicos, como preferência pessoal e hábito, foram relevantes; dessa forma, 39\% dos usuários demonstraram preferência pessoal em utilizar o condicionamento artificial mesmo em condições térmicas e acústicas favoráveis. Assim, o desconforto térmico e o acústico não foram motivos isolados.

As características do edifício, como amplas aberturas, ausência de proteções solares externas, posicionado em avenida ruidosa e constante proximidade dos usuários com as janelas, foram limitantes às atitudes dos usuários identificadas na pesquisa. Conclui-se que, embora a envoltória do edifício estudado possua vidros com baixo fator solar $(0,26)$, seria pertinente incluir outras medidas de eficiência energética, como proteções solares externas ou redução da área de vidro, especialmente na fachada leste, que apresentou uma frequência $20 \%$ maior no uso do ar-condicionado. Desse modo, as análises finais evidenciam a grande influência das decisões projetuais nas variações de uso e operação dos sistemas, dificultando hábitos mais eficientes. Além disso, os fatores de localização dos usuários, orientação solar e tipo dos sistemas são imprescindíveis e devem ser considerados no desenvolvimento do projeto das edificações comerciais.

Por fim, destaca-se que a padronização das ações dos usuários mediante um único padrão de uso para os estudos por simulação computacional não abrange a heterogeneidade existente na ocupação e na operação dos sistemas em edifícios comerciais.

Destaca-se que o presente estudo abrangeu um período curto de análise, sendo oportunas a investigação do comportamento dos usuários ao longo de um ano e a utilização de sistemas de monitoramento in loco.

\section{Referências}

ASSOCIAÇÃO BRASILEIRA DE NORMAS TÉCNICAS. NBR 15220: desempenho térmico de edificações. Rio de Janeiro, 2005.

BAVARESCO, M. V.; GHISI, E. Influence of user interaction with internal blinds on the energy efficiency of office buildings. Energy and Buildings, v. 166, p. 538-549, May 2018.

BAVARESCO, M. V.; GHISI, E. Monitoramento e modelagem da operação de elementos internos de sombreamento em escritórios: uma revisão de literatura. Ambiente Construído, Porto Alegre, v. 21, n. 1, p. 315-334, jan./mar. 2021.

BORGSTEIN, E. H.; LAMBERTS, R.; HENSEN, J. L. M. Mapping failures in energy and environmental performance of buildings. Energy and Buildings, v. 158, p. 479-485, jan. 2018.

BRUGNERA, R. R.; RORIZ, V. F.; CHVATAL, K. M. S. Temperaturas de acionamento de condicionadores de ar e ventiladores. In: ENCONTRO LATINO-AMERICANO DE CONFORTO NO AMBIENTE CONSTRUÍDO, Brasília, 2013. Anais [...] Porto Alegre: ANTAC, 2013. 
D’OCA, S. et al. Human-building interaction at work: findings from an interdisciplinary cross-country survey in Italy. Building and Environment, v. 132, p. 147-159, mar. 2018.

D’OCA, S.; HONG, T. Occupancy schedules learning process through a data mining framework. Energy and Buildings, v. 88, p. 395-408, feb. 2015.

DELZENDEH, E. et al. The impact of occupants' behaviours on building energy analysis: a research review. Renewable and Sustainable Energy Reviews, v. 80, p. 1061-1071, dec. 2017.

FABI, V. et al. Effect of occupant behaviour related influencing factors on final energy end uses in buildings. In: CLIMAMED CONFERENCE, 11., Madrid, 2011. Proceedings [...] Madrid, 2011.

FABI, V. et al. Occupants' window opening behaviour: a literature review of factors influencing occupant behaviour and models. Building and Environment, v. 58, p. 188-198, dec. 2012.

FENG, X.; YAN, D.; HONG, T. Simulation of occupancy in buildings. Energy and Buildings, v. 87, p. 348-359, jan. 2015.

FIELD, A. Descobrindo a estatística usando o SPSS. 2. ed. Porto Alegre: Artmed, 2009.

GAETANI, I.; HOES, P.-J.; HENSEN, J. L. M. Occupant behavior in building energy simulation: towards afit-for-purpose modeling strategy. Energy and Buildings, v. 121, p. 188-204, jn. 2016.

GOOGLE MAPS. [Mapa]. Disponível em: https://www.google.com.br/maps/. Acesso em: 11 jun. 2020.

GUNAY, H. B. et al. Development and implementation of an adaptive lighting and blinds control algorithm. Building and Environment, v. 113, p. 185-199, feb. 2017.

GUNAY, H. B.; O'BRIEN, W.; MORRISON, I. Beausoleil: a critical review of observation studies, modeling, and simulation of adaptive occupant behaviors in offices. Building and Environment, v. 70, p. 31-47, dec. 2013.

HACKBARTH NETO, A. A.; STEIN, C. E. Uma abordagem dos testes não-paramétricos com utilização do Excel. Porto Alegre: Instituto de Matemática e Estatística, UFRGS, 2003.

HALDI, F.; ROBINSON, D. Adaptive actions on shading devices in response to local visual stimuli. Journal of Building Performance Simulation, v. 3, p. 135-153, apr. 2010.

HALDI, F.; ROBINSON, D. On the behaviour and adaptation of office occupants. Building and Environment, v. 43, p. 2163-2177, jan. 2008.

HAN, J.; KAMBER, M.; PEI, J. Data mining concepts and techniques. $3^{\text {rd }}$. ed. Waltham: Elsevier, 2012.

HOES, P.-J. et al. User behavior in whole building simulation. Energy and Buildings, v. 41, p. 295-302, mar. 2009.

HONG, T. et al. Advances in research and applications of energy-related occupant behavior in buildings. Energy and Buildings, v. 116, p. 694-702, mar. 2016.

HONG, T. et al. An ontology to represent energy-related occupant behavior in buildings: part I: introduction to the DNAs framework. Building and Environment, v. 92, p. 764-777, oct. 2015.

HONG, T. et al. Ten questions concerning occupant behavior in buildings: the big picture. Building and Environment, v. 114, p. 518-530, mar. 2017.

HONG, T.; LIN, H.-W. Occupant behavior: impact on energy use of private offices. In: INTERNATIONAL BUILDING PERFORMANCE SIMULATION ASSOCIATION ASIA CONFERENCE, China, Japan, Korea, 2013. Proceedings [...] China, Japan, Korea: IBSPA, 2013.

INSTITUTO NACIONAL DE METROLOGIA, QUALIDADE E TECNOLOGIA. Portaria n 42, de 24 de fevereiro de 2021. Instrução Normativa Inmetro para a Classificação de Eficiência Energética de Edificações Comerciais de Serviço e Públicas (INI-C). Brasília: Inmetro, 2021.

JANDA, K. B. Buildings don’t use energy: people do. Architectural Science Review, v. 54, p. 15-22, jun. 2011.

JIA, M.; SRINIVASAN, R. S.; RAHEEM, A. A. From occupancy to occupant behavior: an analytical survey of data acquisition technologies, modeling methodologies and simulation coupling mechanisms for building energy efficiency. Renewable and Sustainable Energy Reviews, v. 68, p. 525-540, feb. 2017. 
KARJALAINEN, S. Should we design buildings that are less sensitive to occupant behaviour: a simulation study of effects of behavior and design on office energy consumption. Energy Efficiency, v. 9, p. 12571270, dec. 2016.

KUMAR, V.; STEINBACH, M.; TAN, P.-N. Introdução ao Data Mining: mineração de dados. Rio de Janeiro: Ciência Moderna, 2009.

LANGEVIN, J.; GURIAN, P.; WEN, J. Tracking the human-building interaction: a longitudinal field study of occupant behavior in air-conditioned offices. Journal of Environmental Psychology, v. 42, p. 94-115, jun. 2015.

LEITE, L. R.; GUTIERREZ, G. C. R. Estudo do sistema de iluminação e do usuário, em edificação após procedimento de etiquetagem. In: ENCONTRO NACIONAL DE TECNOLOGIA DO AMBIENTE CONSTRUÍDO, 16., São Paulo, 2016. Anais [...] Porto Alegre: ANTAC, 2016.

LIU, A. W. Diretrizes para projeto de edifícios de escritórios. São Paulo, 2010. 249 f. Dissertação (Mestrado em Engenharia Civil e Urbana) - Escola Politécnica, Universidade de São Paulo, São Paulo, 2010 .

MARIANO, D. A. O panorama atual da requalificação de edifícios de escritórios na cidade de São Paulo. São Paulo, 2013. 183 f. Dissertação (Mestrado em Arquitetura e Urbanismo) - Universidade Presbiteriana Mackenzie, São Paulo, 2013.

MARKOVIC, R. et al. Window opening model using deep learning methods. Building and Environment, V. 145, p. 319-329, nov. 2018.

O'BRIEN, W. et al. A preliminary study of representing the interoccupant diversity in occupant modelling. Journal of Building Performance Simulation, v. 10, p. 509-526, 2017.

O'BRIEN, W.; GUNAY, H. B. The contextual factors contributing to occupants' adaptive comfort behaviors in offices: a review and proposed modeling framework. Building and Environment, v. 77, p. 77 87, jul. 2014.

PAN, S. et al. A study on influential factors of occupant window-opening behavior in an office building in China. Building and Environment, v. 133, p. 41-50, apr. 2018.

PISANI, M. A. J.; FIGUEIREDO, E. C. Edifícios de escritórios em São Paulo: tipologias de 1979 a 2010. In: CONFERÊNCIA INTERNACIONAL DA LARES: LATIN AMERICAN REAL ESTATE SOCIETY, 11., São Paulo, 2011. Anais [...] São Paulo: Centro Brasileiro Britânico, 2011.

PISELLO, A. L. et al. How peers' personal attitudes affect indoor microclimate and energy need in an institutional building: results from a continuous monitoring campaign in summer and winter conditions. Energy and Buildings, v. 126, p. 485-497, aug. 2016.

RORIZ, M. Classificação de climas do Brasil. Versão 3.0. São Carlos: Grupo de Trabalho sobre Conforto Ambiental e Eficiência Energética de Edificações, ANTAC, 2014.

ROUSSEEUW, P. J. Silhouettes: a graphical aid to the interpretation and validation of cluster analysis. Journal of Computational and Applied Mathematics, v. 20, p. 53-65, 1987.

RUPP, R. F.; VÁSQUEZ, N. G.; LAMBERTS, R. A review of human thermal comfort in the built environment. Energy and Buildings, v. 15, p. 178-205, oct. 2015.

STATISTICAL PACKAGE FOR THE SOCIAL SCIENCES. The SPSS TwoStep Cluster Component: a scalable component enabling more efficient customer segmentation. New York: IBM, 2011. Technical report.

STAZI, F.; NASPI, F.; D'ORAZIO, M. A literature review on driving factors and contextual events influencing occupants' behaviours in buildings. Building and Environment, v. 118, p. 40-66, jun. 2017.

SUN, C. et al. A longitudinal study of summertime occupant behavior and thermal comfort in office buildings in northern China. Building and Environment, v. 143, p. 404-420, oct. 2018.

SUN, K.; HONG, T. A simulation approach to estimate energy savings potential of occupant behavior measures. Energy and Buildings, v. 136, p. 43-62, feb. 2017.

VECCHI, R. de et al. Thermal comfort in office buildings: findings from a field study in mixed-mode and fully-air conditioning environments under humid subtropical conditions. Energy and Buildings, v. 123, p. 672-683, oct. 2017. 
YAN, D. et al. Occupant behavior modeling for building performance simulation: current state and future challenges. Energy and Buildings, v. 107, p. 264-278, nov. 2015.

YUN, G. Y.; KIM, H.; KIM, J. T. Effects of occupancy and lighting use patterns on lighting energy consumption. Energy and Buildings, v. 46, p. 152-158, mar. 2012.

ZHANG, Y. et al. Rethinking the role of occupant behavior in building energy performance: a review. Energy and Buildings, v. 172, p. 279-294, aug. 2018.

ZHANG, Y.; BARRETT, P. Factors influencing the occupants' window opening behaviour in a naturally ventilated office building. Building and Environment, v. 50, p. 125-134, apr. 2012.

\title{
Agradecimentos
}

Os autores agradecem à Capes pela bolsa de estudo concedida e à aluna de iniciação científica Amanda Matias da Silva pelo auxílio na aplicação dos questionários.

\author{
Jéssica Castoldi Picchi Ciappina \\ Departamento de Construção Civil | Universidade Estadual de Londrina | Rod. Celso Garcia Cid, PR 445, Km 380 Campus Universitário | \\ Londrina - PR - Brasil | Caixa Postal 6001 | CEP 86057-970 | Tel: (43) 3371-4455 | E-mail: jessicapicchi.arq@hotmail.com \\ Mariana Ragassi Urbano \\ Departamento de Estatística | Universidade Estadual de Londrina | Tel: (43) 3371-4848 | E-mail: mrurbano@uel.br \\ Thalita Gorban Ferreira Giglio \\ Departamento de Construção Civil | Universidade Estadual de Londrina | Tel: (43) 3371-4455 | E-mail: thalita@uel.br \\ Jéssica Castoldi Picchi Ciappina \\ Departamento de Construção Civil | Universidade Estadual de Londrina | Rod. Celso Garcia Cid, PR 445, Km 380 Campus Universitário | \\ Londrina - PR - Brasil | Caixa Postal 6001 | CEP 86057-970 | Tel: (43) 3371-4455 | E-mail: jessicapicchi.arq@hotmail.com \\ Mariana Ragassi Urbano \\ Departamento de Estatística | Universidade Estadual de Londrina | Tel: (43) 3371-4848 | E-mail: mrurbano@uel.br \\ Thalita Gorban Ferreira Giglio \\ Departamento de Construção Civil | Universidade Estadual de Londrina | Tel: (43) 3371-4455 | E-mail: thalita@uel.br
}

\section{Ambiente Construído}

Revista da Associação Nacional de Tecnologia do Ambiente Construído

Av. Osvaldo Aranha, $99-3^{\circ}$ andar, Centro

Porto Alegre - RS - Brasil

CEP 90035-190

Telefone: +55 (51) 3308-4084

www.seer.ufrgs.br/ambienteconstruido www.scielo.br/ac

E-mail: ambienteconstruido@ufrgs.br 